\title{
EL CACIQUISME INALTERABLE: LA DIPUTACIÓ PROVINCIAL DE CASTELLÓ EN TEMPS CONVULSOS (1913-1923)
}

\author{
THE UNALTERABLE CACIQUISM: THE \\ PROVINCIAL COUNCIL OF CASTELLÓ IN \\ TROUBLED TIMES (1913-1923)
}

Gerard Llansola Gil Universitat Jaume I

\section{RESUMEN}

En un context marcat pels greus trastorns socioeconòmics i per la fallida del sistema polític, la Diputació Provincial de Castelló s'erigeix en remarcat exponent de la incapacitat del règim de la Restauració i de la seua classe política d'adaptar-se als nous reptes plantejats durant aquesta etapa, situada entre el segon i el tercer decenni del segle XX. Es fa evident la pervivència del predomini de les formes pròpies de la vella política -clientelisme, caciquisme- en l'acció de govern de la corporació provincial i en la gestió de les seves competències. D'aquesta manera, el sotmetiment continuat $d^{\prime}$ aquesta institució a les estratègies clientelars i partidistes en perjudici dels interessos generals de la ciutadania va contribuir de forma substancial al desprestigi i a la pèrdua de suports del sistema polític de la Restauració entre la societat castellonenca.

Palabras clave: caciquisme, clientelisme, Diputació Provincial de Castelló, Restauració, poders locals.

\begin{abstract}
The city of Castellón began to hold Masonic workshops during the period called "Sexenio Revolucionario". In the course of the Restoration, and especially in the 1880s, the structural organisation of Freemasonry became complex, specially the lodges under the auspices of the Great National Orient of Spain. It was then that these actors became the main protagonists of the city's social networks and even participated directly in local politics within republicanism ranks, although this is not discussed in the article. They controlled social centres, such as the "Casino de Artesanos". They relied on publications that supported them and had a proper Masonic publication, "La Razón", that emerged as a defence against anti-Masonic elements evidenced in "La Verdad", amongst other publications. The more plausible results were the "Exposición de Castellón" in July 1887 and the "Exposición de Salinas" of primary instruction.
\end{abstract}

Keywords: caciquism, patronage, Provincial Council of Castelló, Restoration, local power. 


\section{INTRODUCCIÓ}

En correspondència amb un context electoral definit per un elevat grau d'adulteració del comicis, pels pactes i contubernis preelectorals i per la instauració de disposicions legals i de formes d'aplicar les mateixes perjudicials per a la competència; i amb l'articulació de les formacions polítiques dinàstiques mitjançant grups de naturalesa clientelar, les institucions restauracionistes es van distingir per la presència generalitzada de la corrupció i el nepotisme.

Fa ja més de dues dècades I'historiador Manuel Martí (1991) realitzava una profunda dissecció del paper de les diputacions provincials en l'entramat caciquista, mitjançant I'estudi de la Diputació de Castelló durant els primers lustres de la Restauració. ' Les següents pàgines suposen un intent de comprovar si els principals paràmetres que definien
I'actuació de la corporació provincial castellonenca durant els primers anys $d$ 'aquell règim, continuaven vigents durant el seu darrer decenni d'existència; o si, per contra, es poden identificar canvis substancials, indicatius de l'existència d'un procés evolutiu cap a usos i valors més pròxims als que presenten els sistemes democràtics.

En termes generals, dos són els elements principals que marcaren el context de crisi que va envoltar l'edifici institucional restauracionista durant aquella etapa final de vigència del règim liberal, abans de la seua substitució per la dictadura primorriverista.

En el plànol socioeconòmic, la Primera Guerra Mundial va provocar ràpides transformacions, de les quals eixiren molt beneficiats determinats sectors - per l'increment de la demanda exterior i per la substitució d'importacions a l'interior- mentre que d'altres entraven en crisi, per les complicacions en els transports i per la caiguda de la demanda exterior, al no tenir els seus productes la condició de necessaris per a les economies de guerra implantades en els estats bel.ligerants. Paral.lelament es va encetar un pronunciat cicle inflacionari, al reduir-se les importacions i aguditzar-se les dificultats i encariment del transport marí-

1 Totes les referències que apareixen en aquest subapartat relatives a la trajectòria de la Diputació de Castelló durant els primers decennis de règim restauracionista han sigut extretes d'aquest treball de Manuel Martí. 
tim. Aquesta evolució dels preus no va poder ser contrarestada pel creixement dels sous, certament considerable però insuficient per evitar la pèrdua de poder adquisitiu dels treballadors. Tots aquestos trastorns van donar peu a un escenari de forta agitació social, protagonitzada per uns sindicats obrers que es trobaven en plena expansió (Roldán, García Delgado, 1973: 21-24).

Quant a l'economia valenciana, el seu sector principal -l'agricultura agroexportadora centrada en el negoci taronger- va resultar un dels més perjudicats per la conjuntura bèl.lica internacional. Les dificultats cada vegada majors per adquirir fertilitzants, insecticides i altres béns de producció, la creixent incapacitat del material mòbil ferroviari disponible per cobrir la demanda, I'encariment dels materials de confecció i l'espectacular increment dels preus dels nòlits, es combinaren amb la pèrdua de mercats -motivada per la decisió dels països bel.ligerants de restringir les importacions de productes no considerats de primera necessitat, com era el cas de la taronja- $i$ amb la consegüent i formidable disminució dels preus de les collites. En conseqüència, el volum de taronja exportada va caure fins a valors semblants als enregistrats a les darreries del segle XIX (Soler, 1984; Abad, 1988). A La Plana -un dels principals nuclis de l'agricultura tarongera valenciana- naturalment aquesta crisi va tenir una notable incidència.
D'eixa manera, en paral.lel a una acusada elevació de l'emigració, es va encetar una onada de protestes i aldarulls, especialment a les comarques agroexportadores. Aquesta situació es perllongaria durant els anys immediatament posteriors a la fi de la guerra, en entrar en crisi bona part de les branques industrials valencianes afavorides per la conjuntura bèl.lica, mentre perdurava el cicle inflacionista i es retardava la recuperació del sector citrícola (Romeu, 1964: 119-120; Alcázar, 1989; Garrido Herrero, 1987: 128-129).

D'altra banda, des de la perspectiva política, la crisi dels dos partits en què s'articulava el sistema polític canovista -el liberal i el conservador- va originar una multiplicació de grups parlamentaris, un període d'intensa inestabilitat parlamentària $i$ uns governs cada vegada més dèbils. Aquest procés ocorria precisament en un escenari que exigia decisions urgents front a les tensions provocades pel context bèl.lic internacional, de manera que la imatge i la legitimat de les Cambres -i del règim de la Restauració en general- en van sorgir fortament perjudicades (Martorell, Rey, 2006: 32-40; Moreno Luzón, 2014). Més en general, tenia lloc en el marc de l'acceleració de la crisi dels valors liberals experimentada des de l'inici de la Gran Guerra tant en els estats bel.ligerants com en aquells que es mantingueren en la neutralitat, crisi que s'havia engegat a Europa a 
les darreries de la centúria anterior (Rey, 1998: 280-287; Fusi, 1997).

Com van afectar aquest convuls context a la Diputació de Castelló? En quina mesura va ser capaç d'adaptar-se a la nova conjuntura econòmica, social i política? $\mathrm{Va}$ esdevindre un agent rellevant en la posada en marxa d'iniciatives per fer front a la crisi? Va articular mesures de tall regeneracionista en el seu funcionament per tal de fer front a la pèrdua de legitimitat que afectava a les institucions polítiques? A través de l'anàlisi de la gestió econòmica desenvolupada per la corporació provincial durant aquells anys, de la seva actuació com a entitat impulsora i defensora dels interessos econòmics castellonencs, de l'administració de les competències i recursos que tenia assignats $i$ de l'exercici que va fer de la seua funció com a òrgan de control dels ajuntaments, tractarem de donar resposta a aquestes qüestions.

\section{LA HISENDA PROVINCIAL: L'ETERN PRO- BLEMA DEL CONTINGENT}

Els pressupostos ordinaris de la Diputació van descriure una evolució en forma de $u$ en el període 1913 1923. Partint de les $895.648,03$ pessetes de 1913, van anar descendint exercici rere exercici fins a les $704.924,68$ pessetes de 1918 i 1919-20. A partir de l'exercici següent es va invertir dràsticament la tendència $i$ tots els pressupostos es situaren en torn al milió de pessetes, excepte el de 1921-22, que amb 1.201.340,25 pessetes, va superar àmpliament aquella xifra. ${ }^{2}$

Però examinem els capítols que en concret constituïen els pressupostos de la Diputació. Una primera aproximació als mateixos permet comprovar que, a grans trets, tant l'estructura de despeses com la d'ingressos de la Diputació no va variar massa respecte de l'exposada per Martí en el treball ja referit. (Fig 1)

Quant a les despeses, la porció més gran del pastís provincial continuava sent la de beneficència, tònica ja enregistrada en el treball de Martí i en altres treballs sobre les diputacions durant l'època de la Restauració (Esteban, 1991: 139 i ss.; Vallejo, 2007: 553-554; Piqueras, Sanz, 1995: 224, 230 i 234; Alía, Sánchez, 1999: 48-49, 52). De fet es pot afirmar que el seu pes s'havia incrementat respecte als primers anys de la Restauració, ja que va superar en tots els exercicis -menys en el de 1913- el 40\% del total de les despeses $i$ en set d'ells el 50\%. En xifres absolutes les quantitats destinades van anar augmentant, des de les $333.584,65$ pessetes de 1913 fins a les 639.926,99 de 1922-23,

2 El pressupost ordinari corresponent a cada exercici era publicat al Boletín Oficial de la Provincia. La xifra de 1918 i 1919-20 es refereix al pressupost de despeses. El pressupost d'ingressos va ser de $704.987,68$ pessetes. 
Figura 1. Percentatge de cada partida pressupostària respecte del pressupost anual ordinari de despeses ${ }^{3}$

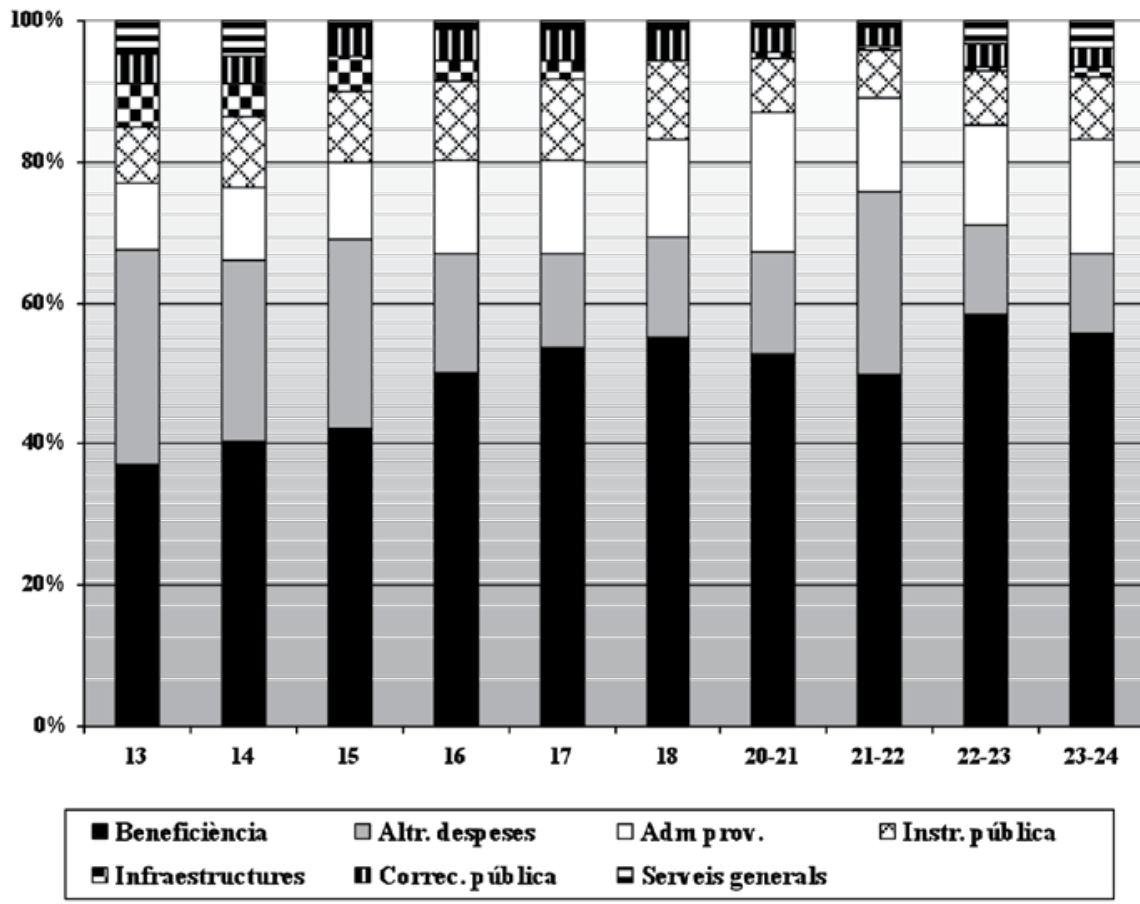

Elaboració pròpia a partir dels pressupostos ordinaris de la Diputació de Castelló publicats al Boletín uuuuuOficial de la Provincia.

però l'increment fou més acusat a partir de 1920-21, exercici a partir del qual ja no baixaren de les 520.000 pessetes i quasi sempre es situaren en torn a les 600.000. La gran majoria d'aquestos diners anaven destinats a l'Hospital Provincial i a la Casa de Misericòrdia i cal recordar que amb ells s'havia de pagar també al personal empleat en aquestos establiments benèfics. Aquest augment de despeses d'assistència social es trobaria relacionat amb el crescut nombre de persones que requerien de la mateixa -conseqüència de la greu crisi econòmica que s'estava patint-, l'elevació dels preus dels subministraments

3 Per a l'exercici 1919-1920 no es va aprovar nou pressupost degut a la situació de bloqueig polític que vivia la Diputació, per la qual cosa es va haver de prorrogar el de 1918. 
i, possiblement també, l'increment del personal per motivacions de naturalesa clientelar.

Com a segon capítol més quantiosament dotat s'havia consolidat el denominat administración provincial, amb percentatges respecte al total de despeses que es situen entre el $9,62 \%$ de 1913 i el $19,72 \%$ de 1920-21, sempre per damunt del $13 \%$ a partir de 1916 , un tant per sobre del $8-11 \%$ enregistrat durant els primers anys de la Restauració. En valors absoluts comencen amb les $86.122,75$ pessetes de $1913 \mathrm{i}$ no baixen de les 150.000 pessetes a partir de 1920-21. Incloïa essencialment despeses de les oficines centrals de la Diputació, de l'arxiu i la dipositaria, de les comissions especials i dels arquitectes provincials. ${ }^{4}$ Entre aquestos conceptes destacava el primer dels enunciats, que contemplava els emoluments del personal de les oficines de la corporació $\mathrm{i}$ les despeses materials de la mateixa i que absorbia més de tres quarts dels recursos assignats a aquesta partida. No s'incloïen en aquesta partida les despeses pressupostades per als serveis de quin- tes, eleccions i elaboració del Boletín Oficial de la Provincia, que junt a un apartat per atendre possibles calamitats eren contemplades en un altre capítol denominat servicios generales, amb uns valors que en cap exercici suposaren en conjunt més del $5 \%$ del total de despeses previstes.

A pesar del seu pes menor val la pena detenir-se breument en l'altre apartat de caire social contemplat en els pressupostos, el d'instrucció pública. Els seus percentatges oscillaren entre el $6,92 \%$ i el $11,32 \%$ respecte del total de despeses, valors semblants als reflectits a l'estudi de Martí i que només en quatre ocasions superen la barrera del $10 \% .^{5}$ Les despeses atribuïdes a aquest concepte anaven destinades a l'Institut de Batxillerat i, en menor mesura -per ordre de més a menys diners assignats- a l'Escola Normal de professores, la Junta Provincial d'Instrucció, biblioteques, museus i, ocasionalment, acadèmies.

Per la seua banda, els capítols destinats a la construcció, manteniment o reforma $d$ 'infraestructures havien experimentat un marcat des-

4 No s'incloïen en aquesta partida les despeses pressupostades per als serveis de quintes, eleccions i elaboració del Boletín Oficial de la Provincia, que junt a un apartat per atendre possibles calamitats eren contemplades en una altra partida denominada servicios generales, amb uns valors que en cap exercici suposaren en conjunt més del $5 \%$ del total de despeses previstes.

5 Quant a xifres absolutes, els marges es situen entre les 69.777 pessetes de 1913 i les 96.350 de 1923-24. 
cens en les seues dotacions -respecte de les obtingudes per Martí per als primers anys de la Restauraciói van assolir un paper absolutament marginal al llarg de l'etapa 19131923. Només en 1913 la suma dels mateixos va superar -i per poc- el $6 \%$ del total de despeses. ${ }^{6}$ La pèrdua d'activitat inversora de les diputacions en infraestructures durant aquell període també ha sigut detectat en altres estudis de cas (Martínez, Laguna, 1995: 266; Cayuela, Abad, 1999: 174). Un altre capítol era el de corrección pública, és a dir, el bastiment i manteniment de presons. A ell es dedicava un percentatge del pressupost de despeses situat entre el 2,64 i el 4,59\%. En darrer terme, els pressupostos de la Diputació es completaven amb una sèrie de partides destinades a atendre càrregues fiscals, assegurances, deutes i censos, pensions, imprevistos, devolucions, obligacions de pressupostos tancats i altres despeses no detallades. Conjuntament assoliren percentatges bastant fluctuants -del 3,92\% de 1923-24 al $25,88 \%$ de 1913 - però que només en quatre ocasions superaren el $10 \%$.
Tot plegat, aquesta aproximació a la hisenda provincial a través dels pressupostos de despeses reforça la idea que la funció primordial de la Diputació com administració pública continuava sent -fins i tot més que abans- la benèfica i assistencial. La resta -instrucció, infraestructures, organització dels processos electorals i de les quintes...- continuaven jugant un paper discret, que en algun cas va esdevenir pràcticament marginal. Al mateix temps, tal com deixa patent l'evolució ascendent del capítol d'administración provincial, la Diputació requeria cada vegada més recursos per tal de desenvolupar les funcions públiques que tenia assignades. És a dir, resultava un organisme més car per als contribuents. (Fig. 2)

Cal passar doncs a preguntar-se per les fonts d'ingressos de què disposava la corporació provincial. En quasi tots els exercicis, més del $95 \%$ dels ingressos pressupostats procediren de l'anomenat contingent provincial, un repartiment entre els pobles de la província de la quantitat necessària per cobrir la diferència entre els recursos propis generats per la Diputació i les despeses de

6 Només dos capítols d'aquest tipus de despeses foren dotats al llarg del període: el d'obras obligatorias, i dins d'ell en concret la partida de reparació i conservació de camins, present només de 1913 a 1915 i amb percentatges que no arribaren al $2 \%$ respecte del total de despeses pressupostades; i el de nuevos establecimientos, amb percentatges situats entre el 5, 18 de 1913 i el 0,14\% de 1918 i 1919-20 i que descriviren, en termes generals, una trajectòria descendent. A la resta de capítols que poden ser inclosos en aquest apartat-el de carreteres, referit a la construcció o subvenció de nous vials, i el denominat obras diversas- no se'ls va assignar cap quantitat en cap dels pressupostos del període. 
la mateixa, repartiment que s'havia de practicar en proporció a allò que cada municipi aportava al Tresor per contribucions directes -rústica, urbana i industrial- i per l'impost de consums. ${ }^{8}$ En xifres absolutes aquest repartiment va oscil.lar entre les $593.472,02$ pessetes de 1913

Figura 2. Percentatge de cada partida pressupostària respecte del pressupost anual ordinari $d^{\prime}$ ingressos ${ }^{7}$

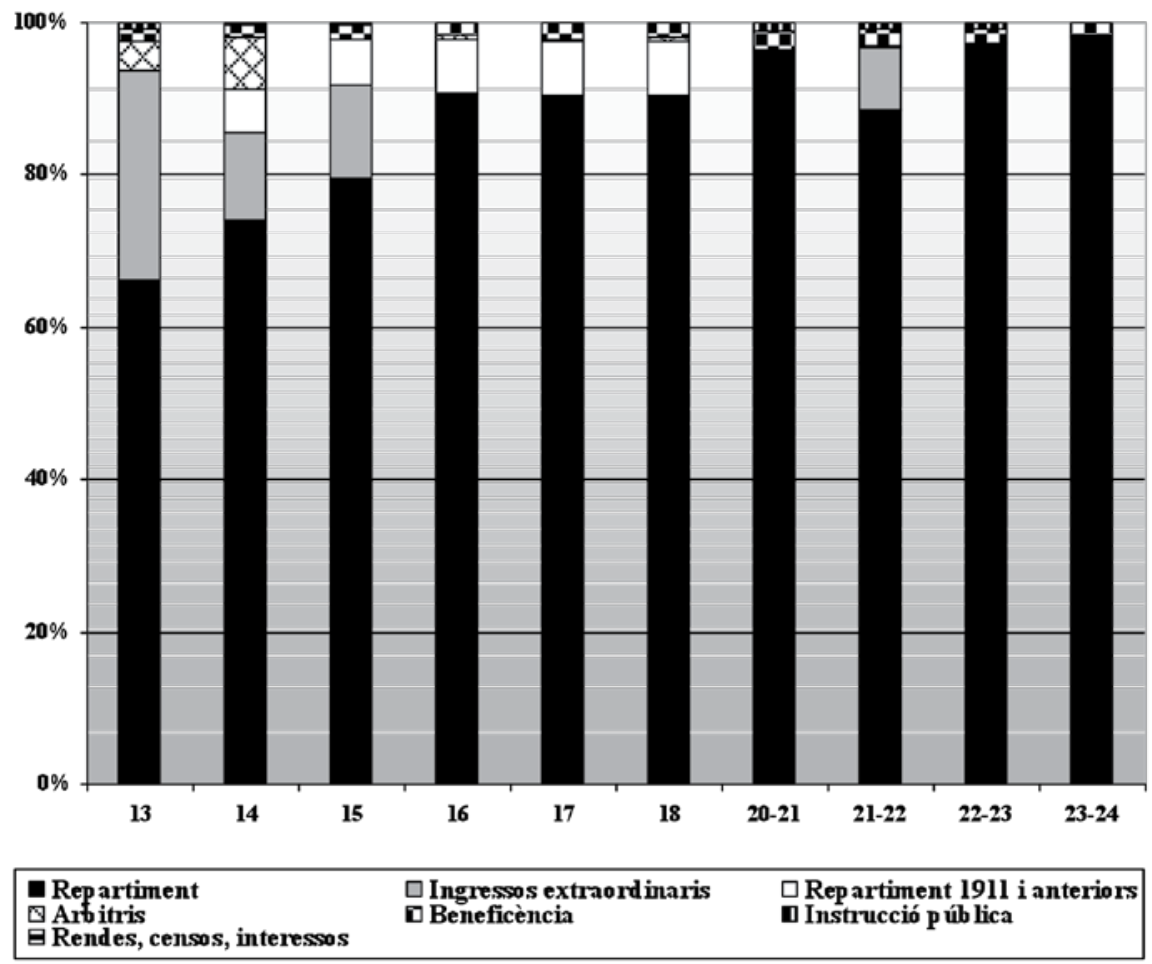

Elaboració pròpia a partir dels pressupostos ordinaris de la Diputació de Castelló publicats al Boletín Oficial de la Provincia.

7 Per a l'exercici 1919-1920 no es va aprovar nou pressupost degut a la situació de bloqueig polític que vivia la Diputació, per la qual cosa es va haver de prorrogar el de 1918.

8 Llei Provincial de 29 d'agost de 1882, article 117, paràgraf segon. En quatre exercicis -1913, 1914,1915 i 1921-22- el percentatge assolit pel contingent-entés com la suma del confeccionat cada any més els crèdits pendents de cobrar de contingents anteriors- no va arribar al $95 \%$-un $66,26 \%$ en 1913 , un $82,24 \%$ en 1914 , un $85,7 \%$ en 1915 i un 88,53 en 1921 22-. Aquesta circumstància va ser deguda no a un descens dels ingressos pressupostats per aquest concepte sinó a la presència de capítols d'ingressos de caràcter eventual, denominats ingresos extraordinarios i arbitrios especiales. 
$i$ les 1.063 .591 pessetes fixades a partir de 1921-22.

Els escassos ingressos pressupostats més enllà del contingent procedien -a banda de recursos puntuals que es produïen eventualment- dels establiments benèfics -entre 12.000 i 25.000 pessetes- dels establiments d'ensenyament-no més de 10.000 pessetes- $d$ 'arbitris especials -amb imports molt variables, però en cap cas superaren les 35.000 pessetes- $\mathrm{i}$ de rendes, censos $\mathrm{i}$ interessos -menys de 200 pessetes-.

Així doncs, s'observa com la hisenda provincial es trobava en una clara posició de dependència respecte del contingent provincial, similar a la ja exposada per Martí en el seu estudi referit als primers anys de la Restauració, posició que es trobava generalitzada en les corporacions provincials d'aquesta època (Alía, Sánchez, 1999: 47; Santos, 2013: 93). Donats aquestos paràmetres, el fet que bona part dels imports corresponents a aquest capítol no s'acabaren cobrant-tal i com venia passant des dels primers anys de l'etapa restauracionista i no sols en la de Castelló, sinó també en d'altres diputacions que han sigut objecte d'estudi (Piqueras, Sanz, 1995: 219-221; Galván, 1994: 940-942)- lògicament deixava els comptes de la Diputació en un situació gens envejable.

En eixe sentit, en el balanç de deu- tes per contingent realitzat en setembre de 1919 eixiren a la llum xifres veritablement alarmants. D'exercicis anteriors a 1911 la Diputació tenia pendent cobrar per aquest concepte un total de $625.043,15$ pessetes. Més preocupant encara era la xifra del deute acumulat durant el període 1911-1918/19: 1.343.189,37 pessetes. Tot plegat aquest ascendia a 1.968.232,52 pessetes. $^{9}$ La forta quantitat de deute per contingent generada en menys de nou anys, de 1911 a setembre de 1919, ha de ser atribuïda en bona mesura a l'etapa de crisi econòmica encetada amb l'esclat bèl.lic internacional i a la seua repercussió en les ja sempre febles hisendes municipals. En tot cas, no es tractava de quantitats inèdites ni inusuals en la trajectòria de la caixa provincial. Ja a principis dels anys 80 , com va posar de relleu Manuel Martí, es parlava d'uns endarreriments per contingent que sumaven en torn al milió i mig de pessetes.

Quatre anys després, i a pesar de l'enèsima bateria de mesures que en aquella sessió plenària de setembre de 1919 s'havia aprovat, la situació en lloc de corregir-se sembla que encara s'havia agreujat més. Així, si fem cas de les dades que en la seua visita al Governador Militar li va facilitar a aquesta autoritat el President de la Diputació, Joaquín Gómez, els pobles devien a la corpo- 
ració provincial en concepte de contingent uns tres milions de pessetes. Per la seua part, els dèbits pendents d'atendre per la Diputació ascendien ja al milió i mig de pessetes. ${ }^{10}$

Però, per què aquesta secular dificultat per recaptar el repartiment distribuït entre els pobles de la província? Més enllà de l'increment de les dificultats de tresoreria de determinats municipis -reflex de la conjuntura de forta depressió econòmica que estaven travessant- les motivacions d'origen polític i caciquista continuaven constituint un gran obstacle per al cobrament del contingent, tal com ja es va posar de relleu a l'estudi de Martí i a d'altres anàlisis de diputacions durant l'època restauracionista (Zurita, 1996: 215-219; Martínez, Laguna, 1995: 255; Galván, 1994: 940-941).

Valga com a mostra la sessió extraordinària que, «[...] teniendo en cuenta el estado económico actual de la Diputación», es va celebrar a principis de 1918, «[...] para tratar ampliamente y adoptar los acuerdos conducentes a la recaudación del contingente provincial y medios de allegar fondos para atender a las obligaciones de su presupuesto». ${ }^{11}$ Al llarg de la mateixa el diputat conservador Domingo Esteller va assegurar que no s'havia d'excloure del procediment d'apremi a cap ajuntament morós, «[...] pues la actual crisis debida a la guerra es igual para todos [...] en casos de negligencia de los alcaldes debía llegarse hasta la suspensión del cargo». Però el més rotund en les seues manifestacions va ser el republicà Vicente Gea, en assenyalar que «[...] el mal de la Diputación es incurable puesto que está en que los de abajo y los de arriba hacemos política y ni un átomo de administración» i que «[...] mientras hay cien pueblos de la provincia que siempre ingresan el total del contingente hay otros que en toda la vida han pagado completos sus cupos». ${ }^{12}$

I és que cap dels diputats volia que els municipis del seu districte foren els més castigats en l'aplicació dels medis extraordinaris de recaptació que la legislació permetia en

10 La Provincia Nueva, 11/10/1923. En la referida sessió de setembre de 1919 havia sigut aprovat l'establiment de concerts amb els pobles amb l'objecte de donar facilitats per al pagament dels endarreriments per contingent. Unes setmanes després es va concretar aquesta fórmula: els deutes serien els corresponents a l'exercici de 1918 i anteriors; els pagaments es materialitzarien en quinze quotes anuals d'igual import; $i$ es requeriria als consistoris municipals implicats que formalitzaren el referit concert amb un acord municipal, acreditat per l'alcalde mitjançant la corresponent certificació. En setembre de 1921 cinquanta-dos ajuntaments encara no havien enviat la citada certificació (Actes de la Diputació Provincial de Castelló, 16/09/1919 i $31 / 10 / 1919 ;$ Actes de la Comissió Provincial, 03/09/1921)

11 Actes de la Comissió Provincial, 16/02/1918.

12 Actes de la Diputació Provincial de Castelló, 04/03/1918. 
cas d'impagaments continuats, degut als costos polítics que aquesta circumstància els podia ocasionar. Procuraven que les seues zones d'influència, els pobles que constituïen el nucli del seu cacicat, no foren apremiats a pagar. També continuaven presents les acusacions relatives a que els municipis més grans eren tractats amb major condescendència en els procediments executius engegats per recaptar els crèdits pendents. ${ }^{13} \mathrm{El}$ pes polític i electoral superior d'aquestes localitats es trobava darrere d'aquest plus de permissivitat. ${ }^{14}$

Les dades oficials per municipis sobre els deutes per contingent efectivament mostren que, en proporció al percentatge de repartiment que tenien assignat, els de majors dimensions en termes generals tenien més deute acumulat que la resta. ${ }^{15}$ A data de 8 d'octubre de 1919, els 25 pobles que tenien més de 3.000 habitants aglutinaven conjuntament el $82,14 \%$ del total de deute acumulat per contingent, mentre que la quantitat assignada a aquest grup de localitats en el repartiment efec- tuat per a l'exercici 1919-1920 només assolia el 65,07\%. Per contra, en el grup de pobles de menys de 3.000 habitants el percentatge respecte del total del repartiment $-34,93 \%$ - pràcticament doblava al del deute acumulat $-17,86 \%$ Si prenem com a referència el grup dels 10 municipis de més de 6.000 habitants les diferències entre els percentatges de quota assignada $-45,96 \%$ - i els de deute acumulat $-74,97 \%$ - encara s'eixamplen més. ${ }^{16}$ (Fig. 3)

En el marc d'aquestes acusacions a les poblacions de majors dimensions, dos foren els municipis que concentraren el major nombre de retrets: Vinaròs i Castelló de la Plana. Respecte al primer, a la vista de les dades disponibles es pot afirmar que les recriminacions estaven justificades. Era el municipi que més diners devia per contingent, 429.226,25 pessetes en octubre de 1919, més d'una cinquena part del total del deute provincial per aquest concepte. Sabem que per aquest motiu a l'alçada d'abril de 1921 la

13 Vegeu per exemple Heraldo de Castellón, 22/11/1917 i 22 i 23/04/1920; actes de la Diputació Provincial de Castelló, 03/08/1920.

14 Així ho expresaba el republicà José de la Torre en juliol de 1919: «Si pagan los pueblos más miserables de la provincia, ¿̇por qué no pagan los ricos? La contestación a esta pregunta la tienen los votos. Mientras Corachar, Chodos, etc., apenas sí llegan a 40 votos, Vinaroz, Villarreal, etc., deciden una elección» (El Clamor, 12/07/1919).

15 Les dades de deutes de contingent per municipi que s'exposen en els següents paràgrafs han sigut recollides del Boletín Oficial de la Provincia, 29/10/1919.

16 El repartiment del contingent per a l'exercici 1919-1920 al Boletín Oficial de la Provincia, $27 / 06 / 1919$. 
Figura 3. Deute per contingent dels municipis amb més de 6.000 habitants en octubre de 1919 (en percentatges respecte al total provincial de deute per contingent $\mathrm{i}$ en valors absouts)

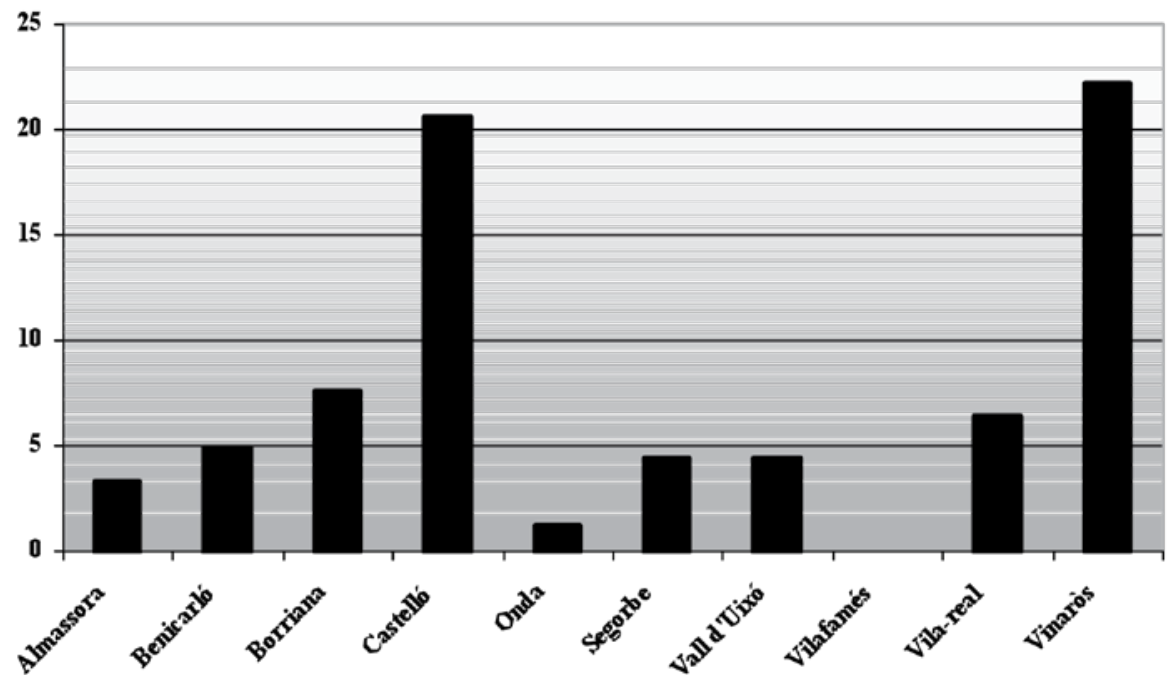

Elaboració pròpia a partir de les dades de deutes de contingent per municipi publicades a Boletín Oficial de la Provincia, 29/10/1919.

Diputació tenia embargada la seua caixa municipal. ${ }^{17}$ Seguint amb el repartiment de l'exercici 19191920, contribuïa amb una quota que suposava el $3,54 \%$ del total, però per contra el seu deute constituïa el 22,20\% de la suma total que devien els pobles a la Diputació.

En el cas de Castelló de la Plana, el deute també ascendia a quantitats considerables. Amb 398.319,43 pessetes, era, després de Vinaròs, el segon municipi en el rànquing de deutors, bastant allunyat del tercer i del quart Borriana -146.399,89 pessetes- i Vila-real -124.727,96 pessetes- respectivament. ${ }^{18} \mathrm{Amb}$ tot, les dades objectives disponibles

17 Actes de la Diputació Provincial de Castelló, 15/04/1921.

18 La situació no havia variat molt en octubre de 1923, quan en sessió plenària el president de la Diputació va informar que els endarreriments acumulats en el pagament del contingent per part de l'Ajuntament de Castelló ascendien a 368.775,66 pessetes (Actes de la Diputació Provincial de Castelló, 22/10/1923). 
palesen que la desproporció entre el percentatge de deute acumulat $i$ el de contingent assignat era molt menor en el cas de Castelló que en el de Vinaròs. Si en aquesta darrera localitat, com ha s'ha comprovat, hi havia quasi 20 punts percentuals de diferència entre ambdues magnituds, a Castelló aquesta no arribava als tres punts percentuals. La capital tenia assignat el 17,69\% del total de contingent anual pressupostat $i$ acumulava el $20,60 \%$ de la quantitat que en conjunt devien els pobles per contingent. En eixe sentit, aquesta proporció entrava dins de la normalitat, era semblant a la que presentaven, per exemple, altres pobles de dimensions considerables, com Borriana -5,41\% i 7,57\% respectivament- o la Vall d'Uixó $-2,19 \%$ i $4,36 \%$ respectivament-.

Més enllà d'aquestos casos concrets, allò que cal remarcar és que la major contribució de les poblacions més grans al deute per contingent no ha de sorprendre, si tenim en compte que en elles concorrien els dos tipus de factors que venim barallant per tractar de comprendre aquest fenomen. D'una banda, els de naturalesa política, ja que es tractava dels municipis amb major influència política i pes electoral. De l'altra, els econòmics. En eixe sentit cal tenir en compte que la zona de la Plana, amb una forta crisi econòmica, era on es concentra- ven la major part dels nuclis urbans de majors dimensions. Fora d'ella, altres pobles grans, com ara Vinaròs, també estaven travessant greus penúries financeres.

En qualsevol cas, el perllongament i l'agudització de la incapacitat per recaptar el contingent provincial, donat el seu pes en el pressupost provincial, havia de tenir repercussions. Així, ja a finals de febrer de 1916, el diari La Provincia dibuixava un escenari en el qual les subhastes per contractar els subministres destinats a l'Hospital i a la Casa de la Misericòrdia acabaven desertes per manca de postors, els empleats encara no havien cobrat la mensualitat de gener, l'empresa que proporcionava fluid elèctric a aquest darrer establiment amenaçava amb tallar-lo si no començava a cobrar allò que se li devia i, entretant, el president-Cristóbal Aicart- i altres dos diputats liberals -Norberto Ferrer i Manuel Giménez- havien marxat a la Cort per atendre interessos purament partidistes, però repercutint els diners del viatge en la caixa provincial. ${ }^{19}$ Amb tot, a pesar que aquestes informacions de l'òrgan dels conservadors no foren desmentides, no és improbable que resultaren un tant exagerades, si tenim en compte l'interés de La Provincia en desacreditar la gestió que venien fent al front de la corporació provincial els seus principals adver- 
saris polítics, els liberals.

En novembre de 1917 era $\mathrm{He}$ raldo de Castellón qui tornava a encendre les alarmes, en assegurar que als empleats de la corporació els devien tres mensualitats i als abastidors dels referits establiments vuit, mentre els diputats de la Comissió Provincial havien cobrat puntualment les dietes del mes d'octubre. ${ }^{20}$ Tanmateix, també cal acollir amb certa precaució aquestes informacions ja que Heraldo de Castellón, diari pròxim al cantisme -la facció provincial del Partit Liberal encapçalada per Vicente Cantos- en aquells moments podia ser considerat un medi contrari a la majoria que governava la Diputació, constituïda per una coalició formada per conservadors, reverteristes -una altra facció liberal castellonenca, comandada per Juan Navarro-Reverter Gomis- i carlins.

En qualsevol cas, poc després emergiren també greus dificultats per atendre les obligacions fiscals. En juliol de 1918 la Diputació va sol.licitar la suspensió del procediment d'apremi dictat contra ella per la Delegació d'Hisenda en Castelló per dèbits al Tresor. De res li va servir aquest prec, com tampoc el recurs d'alçada posterior, desestimat pel Tribunal Governatiu del Ministeri d'Hisenda a principis de 1920. En abril d'eixe any la suma que la corporació provincial devia al fisc ascendia ja a 413.697,20 pessetes. ${ }^{21}$ Situacions d'endeutament similar amb la hisenda estatal es donaren en altres diputacions durant el període restauracionista (Galván, 1994: 948-949).

Paral-lelament, les relacions amb els proveïdors també s'anaven degradant. A finals de 1919 els contractistes del subministrament de pa i oli per als establiments provincials sol-licitaren la rescissió dels contractes respectius, pels continuats impagaments de la Diputació. ${ }^{22}$ En la mateixa línia, en març de 1920 els contractistes de subministraments visitaren al Governador Civil per anunciar-li que si en uns dies la Diputació no saldava els deutes acumulats amb ells durant l'any anterior, deixarien d'abastir els establiments provincials. En setembre el subministrador de la carn per als establiments provincials havia sol.licitat la rescissió del contracte, però en última instància es va aconseguir que accedira a continuar subministrant aquest article i a més amb una rebaixa de 20 cèntims per kilogram, a canvi de cobrar setmanal-

20 Heraldo de Castellón, 22 i 24/11/1917.

21 La Provincia Nueva, 27/07/1918, Actes de la Comissió Provincial, 20/01/1919 i Actes de la Diputació Provincial de Castelló, 10/04/1920.

22 Actes de la Comissió Provincial, 28/11/1919 i 15/12/1919. 
ment. També demanaren la rescissió els subministradors de llet i de cansalada, però la Diputació, després de demanar fins $i$ tot el suport del Governador Civil i sense que transcendiren els arguments que va esgrimir, es va negar a resoldre ambdós contractes. En novembre de 1920 el contractista del pa va remetre una instància a la Comissió Provincial, en la qual posava de manifest que portava des del mes de juliol sense percebre cap tipus d'honorari i que la quantitat que li devia la corporació ascendia ja a "[...] algunos miles de duros». En gener de 1921, el contractista de la llet requeria que se li abonaren els pagaments de setembre i octubre i es va acordar passar aquesta petició a l'ordinador de pagaments, «[...] para con ello evitar que deje de suministrar el contratista desde $1^{\circ}$ de febrero la leche a los establecimientos». ${ }^{23} \mathrm{Per}$ aquells mateixos anys problemes similars per proveir-se de subministraments es donaven a la Diputació de València (Martínez, Laguna, 1995: 255 i 259 ).

Cal tenir en compte que posar fi a tots aquestos contractes, adjudicats per subhasta, suposava que la Diputació haguera d'adquirir els productes a preus de mercat, més elevats i que a més s'havien de pagar al comptat. A l'estiu de 1921 el Ministeri de Governació va haver de concedir una autorització a la Diputació per la qual quedara eximida del tràmit de subhasta a l'hora de contractar proveïdors per als referits establiments, donat que totes les darreres subhastes que s'havien celebrat havien quedat desertes. I en octubre d'aquell any el diputat Miguel Llansola assenyalava que la corporació havia d'adquirir les medicines i demés material sanitari per a l'Hospital i la Casa de Misericòrdia directament en les farmàcies, perquè, donada la seua fama de mal pagadora, els magatzemistes majoristes es negaven a proveir-la $d^{\prime}$ aquestos articles. ${ }^{24}$

Així doncs, tenint en compte el quadre econòmic de la Diputació perfilat en les anteriors línies i la seva evolució al llarg del període 1913-1923, es pot afirmar que durant aquesta etapa l'erari provincial, tot partint d'una situació certament poc encoratjadora, es va debilitar encara més, en agreujar-se la seva incapacitat recaptatòria. La

23 L'anunci dels contractistes a Heraldo de Castellón, 10/03/1920. Les successives peticions de rescissió dels contractes a Actes de la Comissió Provincial, 03/09/1920, 26/11/1920 i 21 i 22/01/1921 i Actes de la Diputació Provincial de Castelló, 13/10/1920. La instància del contractista del subministrament del pa a Actes de la Comissió Provincial, 13/11/1920.

24 La qüestió de les subhastes i l'exempció d'aquest tràmit a Actes de la Comissió Provincial, 18/06/1921 i Actes de la Diputació Provincial de Castelló, 08/08/1921. Les dificultats per abastir-se de material sanitari i medicaments a La Provincia Nueva, 14/10/1921. 
irrupció d'una conjuntura econòmica força difícil per a molts municipis del territori castellonenc junt a la persistència en l'ús partidista, caciquista, de la hisenda provincial, no podien donar un altre resultat.

\section{Foment Dels INTERESSOS PROVINCI- ALS: UNES LIMITACIONS MANIFESTES}

A banda de les funcions burocràtiques assignades a la Diputació -en l'esfera de l'administració local i en l'electoral- ja s'ha observat al punt anterior com també exercia competències en els àmbits assistencial i educatiu i en la dotació d'infraestructures públiques. En l'anàlisi del pressupost de despeses s'ha comprovat que en aquest plànol d'activitat l'acció de la corporació provincial es concentrava principalment en la beneficència. En molta menor mesura en l'ensenyament i els equipaments culturals i de manera pràcticament marginal en la conservació i dotació d'infraestructures -carreteres i camins essencialment$i$ en el manteniment de les presons.

És a dir que, donada la seua debilitat financera, la Diputació va limitar cada vegada més els seus esforços a mantenir uns serveis, els benèfics, que -en aquella societat amb tantes desigualtats i que a més estava travessant una greu crisi econòmica- esdevenien bàsics, tot arraconant a un plànol molt secundari les estratègies i projectes de tall de- senvolupista i en la mateixa línia seguida per corporacions homòlogues en altres províncies (Zurita, 1996: 215-219; Galván, 1994: 953-954, 1132; Santos, 2013: 93-95).

La inactivitat quasi absoluta que la corporació provincial va jugar en aquestos àmbits d'actuació va alçar protestes entre diversos sectors de la societat castellonenca, reticents a conformar-se amb que la corporació provincial, sufragada $a m b$ recursos de tots els ciutadans, renunciara a exercir d'agent impulsor del seu desenvolupament material i intel.lectual.

Aquesta línia argumental crítica amb la labor de la Diputació es va veure reforçada per una sèrie d'episodis que van anar sorgint al llarg del període i que assoliren una considerable ressonància pública. Un d'ells es va encetar quan a principis de setembre de 1914 es va donar a conèixer un decret que prohibia impartir ensenyaments de magisteri en els instituts de batxillerat. Eixe era el cas en què es trobava Castelló, que no disposava de cap Escola Normal de professors, denominació que rebien els centres educatius que tenien la funció específica de formar als futurs mestres d'ensenyament primari. Les despeses per sufragar la creació d'aquest tipus d'institucions educatives havien de ser assumides per les diputacions. ${ }^{25}$

De seguida es va iniciar una

25 Sí que existia una Escola Normal de professores, mantinguda per la Diputació. 
campanya a favor de la creació de I'Escola Normal, impulsada per la premsa local i secundada també per l'Ajuntament de la capital. Entre les raons esgrimides a favor del projecte es va argumentar que només hi havia altres tres capitals que mancaven d'aquest tipus de centre i que el cost del projecte -xifrat en unes 32.000 pessetes- era perfectament assumible per la Diputació i seria compartit amb el consistori municipal castellonenc, que també hi contribuiria. ${ }^{26}$

Nogensmenys també ben prompte des de la premsa dels conservadors -que en aquells moments constituien la principal minoria en una corporació provincial governada pel Partit Liberal- es va assegurar que el projecte no prosperaria, perquè els liberals tenien por a que tractar la qüestió de l'Escola Normal provocara escletxes i acabara trencant el grup majoritari que controlava la Diputació. I és que La Provincia assenyalava que recents nomenaments de personal havien generat fortes discrepàncies entre cantistes i reverteristes, fins al punt que la unió, sempre fràgil, d'ambdues faccions liberals-que constituien conjuntament la majoria governant a la corporació- corria risc seriós de ruptura. ${ }^{27}$

A pesar que en darrer terme l'afer sí que fou abordat en sessió de la Diputació i que no va acabar desencadenant la fallida de la majoria liberal -tot i que es va rumorejar la possible dimissió de Cristóbal Aicart, vicepresident de la Comissió Provincial- el ben cert és que el vaticini del diari conservador sobre la sort final que correria el projecte de I'Escola Normal sí que es va complir.

La pressió popular va arribar fins a la celebració d'un míting, organitzat pel Centre Obrer, que va comptar amb la intervenció de dirigents obrers, de destacats polítics republicans -Gasset, Santa Cruz, Selmade membres de la premsa local de totes les tendències, d'estudiants, professors $i$ inspectors educatius $i$ del president del Cercle Mercantil i que a més va rebre les adhesions d'entitats tan diverses com el Casino d'Artesans, la Joventut Socialista, el Cercle Legitimista, la Cambra Agrícola, la Cambra de Comerç o el Cercle Conservador. Tanmateix, en sessió plenària de 21 d'octubre, la majoria liberal va posar fi a tota esperança. Això suposava el seu vot en contra de sengles propostes de les minories conservadora i republicana que -en oposició a la tesi de la Comissió d'Hisenda, que havia dictaminat que la institució no es trobava en condicions d'afrontar el

26 La campanya i els seus arguments es poden seguir entre altres als números de setembre i de principis d'octubre de 1914 dels tres diaris de la capital -El Clamor, Heraldo de Castellón i La Provincia- i del periòdic obrer El Amigo del Pueblo.

27 La Provincia, 05/09/1914. 
cost de la creació de l'Escola Normal- defenien que aquesta sí que era econòmicament viable. ${ }^{28}$

Resulta inviable determinar amb nitidesa els motius que dugueren a la majoria liberal de la corporació a rebutjar el projecte. Tal volta temeren, efectivament, posar en perill la seua cohesió interna com a grup majoritari; o més aviat no volien comprometre uns fons que podien necessitar per a dur a terme maniobres clientelars i caciquistes, tan habituals en aquella institució, més encara tenint en compte que ja no faltava tant per a les properes eleccions provincials, a celebrar en març de 1915; o és possible que pensaren, sincerament, que les despeses del nou centre ofegarien greument la ja complicada hisenda provincial; o tal volta una combinació de tots o alguns d'aquestos factors.

És cert, en tot cas, que la qüestió de l'Escola Normal va esdevenir, inevitablement, un arma política més, en aquest cas usada per republicans i conservadors, per blasmar la gestió de la corporació provincial. Però també és innegable que la frustració d'aquella iniciativa va traspassar l'arena política i va deixar un amarg regust en la societat, particularment en els estudiants professors de magisteri $i$ en les organitzacions obreres, que de bon principi s'havien mostrat activament favorables a un projecte que estimaven clau perquè els treballadors no perderen possibilitats $d^{\prime}$ accedir a estudis superiors i poder així millorar les seves oportunitats professionals. ${ }^{29}$ Al mateix temps, va reforçar els arguments dels republicans en contra, ja no d'un grup polític en concret, sinó de la Diputació com a institució. No desaprofitaren l'ocasió de subratllar que una vegada més havia quedat demostrada la inutilitat d'una corporació que sempre actuava d'esquenes a tota reforma de progrés. ${ }^{30}$ Fins i tot va suscitar crítiques en les pròpies files liberals, almenys en el seu portaveu a la premsa, Heraldo de Castellón. ${ }^{31}$

Dos anys després, però, els libe-

28 Els rumors sobre el malestar i possible dimissió d'Aicart a Heraldo de Castellón, 21 i 22/10/1914 i El Clamor, 22 i 23/10/1914. La crònica del míting pro Escola Normal a El Clamor i Heraldo de Castellón, 09/10/1914. La crònica de la sessió en què es va desestimar la creació de l'Escola Normal a les Actes de la Diputació Provincial de Castelló, 21/10/1914 i La Provincia i El Clamor, 22/10/1914.

29 Crítiques de professors a la decisió de no crear l'Escola Normal a La Provincia i El Clamor, 24 i 27/10/1914. Queixes dels dirigents del Centre Obrer a El Clamor, 26/10/1014 i La Provincia Nueva, 26 i 27/10/1914.

30 L'animadversió contra la Diputació formava part del discurs polític republicà (LLANSOLA, G.: Republicanisme, identitat popular i hegemonia municipal. Castelló de la Plana, 1913-1917. Universitat Jaume I, Castelló de la Plana, 2006, pp. 140-141). En aquest sentit s'arribava fins a demanar la supressió d'aquestos organismes, com va fer El Clamor en finalitzar un període de 
rals continuaven regint els destins de la màxima institució provincial. Es podria elucubrar amb la possibilitat que el bloqueig efectuat al projecte de l'Escola Normal els haguera perjudicat en alguna mesura als comicis provincials de març de 1915, quan només la seua còmoda dominació al districte de Llucena-Viver i la polèmica anulació de l'acta del carlista Bellido al de Castelló els va permetre -després de pactar secretament amb dos diputats conservadors- mantenir-se com a força de govern. Però el ben cert és que en aquella tardor de 1916 tornaren a jugar un paper molt similar en un altre episodi d'una factura i un desenvolupament semblants al de la Normal, el generat en torn a la possibilitat de crear una escola pericial, «[...] donde pudiera el pueblo que trabaja, el que produce la riqueza y por lo tanto el contingente provincial, acudir a aprender algo de lo mucho que ignora y que nece- sita para defenderse en las luchas de la vida».32

Van haver però certes diferències. La iniciativa en aquest cas va partir de l'esfera política i més en concret del diputat provincial republicà $\mathrm{Vi-}$ cente Gea. No va gaudir de tanta ressonància mediàtica i popular com la de l'Escola Normal i no va rebre el suport ni dels liberals ni dels conservadors. Però els termes principals del combat dialèctic corresponent sí que van coincidir: mentre els oponents al projecte esgrimien el seu elevat cost com a principal argument, els republicans defenien que figuraven partides perfectament prescindibles en el pressupost -30.000 pessetes per a imprevistos, 14.500 per a dietes i despeses de representació dels diputats, 14.891 per a dotació de personal temporal (amics polítics en molts casos) ....$-{ }^{33}$ I el resultat fou, en últim terme, idèntic, el rebuig majoritari dels diputats provincials a posar en marxa el projecte.

sessions que, segons el seu criteri, havia resultat novament decebedor: «¿Ahora a esperar otro periodo semestral? ¿2Para qué? De la Diputación no hay que esperar nada; fiel prototipo de los demás organismos monárquicos, su misión no es otra que servir al régimen aunque para ello tengan que perecer los pueblos. Lo que debiera hacerse, eso sí, es pedir a los poderes públicos que desparezcan las diputaciones, por inservibles y perniciosas» (El Clamor, 25/11/1915). Un any després l'òrgan republicà va tornar a insistir, després de repassar cadascuna de les funcions de les diputacions i assegurar que les podien assumir i exercir més satisfactòriament altres institucions (El Clamor, 09/12/1916). Un altre exemple a El Clamor, 12/07/1919.

31 El Clamor, 22 i 23/10/1014. Les crítiques d'Heraldo de Castellón a la postura de la majoria liberal contrària a la creació de l'Escola Normal a Heraldo de Castellón, 21 i 22/10/1914.

32 El Clamor, 22/11/1916.

33 Vegeu les edicions d'El Clamor, Heraldo de Castellón i La Provincia Nueva dels dies 17 a $24 / 11 / 1916$. 
Igualment, tal com havia fet en el cas de la Normal, també Heraldo de Castellón es va mostrar crític amb aquella nova negativa. No ens resistim a il.lustrar aquesta postura del diari liberal amb el següent paràgraf, que denota també fins a quin punt la reputació de la Diputació es trobava degradada, fins i tot en els cercles dinàstics:

Había en los liberales la misma resistencia que en los diputados conservadores a la proyectada Escuela Pericial del reputado doctor Gea. Y es natural: esa Escuela no es un recurso vulgar contra elecciones no menos vulgares; no es la multa impuesta al tío Juan de Sacañet, por haberle guiñado el ojo malo a S.M. el Cacique lugareño, ni siquiera es esa Escuela Pericial del famoso doctor Gea la colocación de un barbero en la Misericordia o en el Hospital, que es para lo único que hay calor en el Palacio Provincial y se provocan reñidas votaciones. Escuela Pericial, servicios de Beneficencia, transformación de los Hospicios... Música, todo eso es música: cada cual se ha acomodado ya y ha acomodado a los suyos en las distintas dependencias de la Diputación y... a vivir. El cosi enseñó a todos a hacer lo propio y el que esperaba otra cosa debe resignarse a ese fraude o emigrar, porque aún está amenazado de mayores decepciones en este país en que todos, caciques i caciquillos, llevan en el vientre un abuelo Pantorrilles. ${ }^{34}$

Les limitacions de la Diputació a I'hora d'impulsar els interessos provincials també es van fer patents en l'afer de l'arbitri de l'arròs. A principis de 1920 el Ministre d'Abastiments autoritzava a la Diputació de Castelló a establir una càrrega fiscal de caràcter eventual, que gravava les exportacions del referit cereal pels ports de la província amb una taxa de cinc pessetes per cada 100 kilograms. ${ }^{35}$ La intenció del Govern al establir aquest tipus d'arbitri era que els recursos recaptats foren invertits en obres públiques, preferiblement relacionades amb el conreu de l'arròs. En eixe sentit, la Diputació fins i tot va obrir una informació pública perquè ajuntaments $\mathrm{i}$

34 Heraldo de Castellón, 22/11/1916.

35 El Clamor, 28/02/1920, Actes de la Diputació Provincial de Castelló, 12/03/1920 i Boletín Oficial de la Provincia, 04/04/1920. La possibilitat de poder sol.licitar al Govern la concessió d'aquest tipus d'arbitri havia sigut atorgada a totes les diputacions provincials per Reial Ordre de 5 de desembre de 1919. 
entitats agrícoles de municipis productors o exportadors d'arròs feren arribar els projectes en els quals proposaven que foren invertits els diners recaptats amb l'arbitri, que ascendiren a $75.929,78$ pessetes. ${ }^{36}$

Però arribat el moment, els liberals -majoria a la corporació- proposaren emprar aquestos recursos en reposar el rober de la Casa de la Misericòrdia i l'instrumental quirúrgic de l'Hospital, que no havien pogut ser renovats durant els darrers anys, segons esgrimien «[...] por lo modesto de las consignaciones en los presupuestos ordinarios» i per l'enorme elevació de preu dels referits articles. La minoria conservadora ciervista -facció d'abast estatal liderada per Juan de la Cierva- en principi es va oposar, per entendre que «[...] las disposiciones legales que crearon el arbitrio [...] lo hicieron con el fin de destinar sus productos al fomento y mejoramiento del cultivo del arroz». Tanmateix, després d'introduir-se diverses esmenes en la proposta inicial dels liberals i després que aquestos insistiren en la penosa situació que estaven travessant ambdós establiments provincials, que segons ells requeri- en la realització urgent d'inversions si es volia evitar el seu tancament en un termini breu, es va acordar per unanimitat el següent pressupost extraordinari per gestionar els diners de l'arbitri: menjador de l'Hospital 4.292,21 pts.; reposició de robers i vaixelles de l'Hospital i la Misericòrdia 45.500 pts.; obres públiques $26.137,57$ pts. ${ }^{37}$ Fins i tot les files ciervistes acabaren assenyalant que «[...] podrá tal o cual comarca tener derecho a tal o cual camino o mejora material, pero de lo que no se les puede privar a sus enfermos y sus pobres es de la alimentación y de la ropa, de lo que carecerán si en esta $u$ en otra forma no se fomentan los ingresos provinciales». ${ }^{38}$

Així, ni la dubtosa legalitat d'aquesta distribució dels ingressos obtinguts per l'arbitri ni l'oposició a la mateixa de l'Ajuntament de Vinaròs -pel port del qual s'havia exportat la major part de l'arròs objecte de l'arbitri- impediren la seua aplicació. Fins i tot els representants provincials en Corts treballaren conjuntament per arrancar del Govern el seu consentiment a que part dels diners recaptats per l'arbitri foren invertits en beneficència. A mitjans

36 Actes de la Diputació Provincial de Castelló, 12/03/1920 i Boletín Oficial de la Provincia, 04/04/1920.

37 Actes de la Diputació Provincial de Castelló, 03/01/1921 i Actes de la Comissió Provincial, 21/03/1921.

38 La Provincia Nueva, 10/02/1921. 
de març de 1921 es donava a conèixer l'aprovació del pressupost extraordinari. ${ }^{39}$

Una vegada més, donada la precària situació econòmica, la realització d'inversions en projectes desenvolupistes en bona mesura havia sigut sacrificada al manteniment dels serveis bàsics. En aquest cas, però, amb la destinació a beneficència d'uns recursos generats i recaptats expressament per ser invertits en obres públiques, la incapacitat de la Diputació com a institució de foment dels interessos provincials va quedar especialment palesada.

D'altra banda, però en correspondència amb aquest discret paper de la corporació provincial com agent dinamitzador de l'economia castellonenca, cal fer referència també al rol secundari que va jugar en l'articulació de moviments de defensa i reivindicació dels interessos de la província, engegats al caliu dels greus trastorns que es succeïren a partir de l'esclat de la Primera Guerra Mundial. Tant en la problemàtica de les subsistències, com en la forta crisi del negoci taronger, com en les polèmiques aranzelàries $\mathrm{i}$ fiscals que travessaren tot el període, la Diputació es va limi- tar a participar en les assemblees programades i a remetre escrits de demanda al Govern, ${ }^{40}$ però en cap cas es pot assenyalar que es comptara entre les entitats que lideraren aquestes iniciatives. Tal línea d'actuació contrasta un tant amb l'adoptada per altres diputacions -València, Canàries- en províncies també molt negativament afectades per la conjuntura socioeconòmica, les quals es posaren al front de les diverses campanyes organitzades des d'aquells territoris (Martínez, Laguna, 1995; Galván, 1994: 10991100). Tot plegat, ens trobem davant d'una mostra més de les limitacions de la Diputació de Castelló a I'hora de representar els interessos de la província, ni tan sols els dels sectors burgesos, que constituïen el suport social del règim.

\section{Gestió interna: bloqueig I paràlisis}

Pel que fa a la seua labor merament administrativa, la imatge de la Diputació tampoc va eixir massa ben parada durant aquestos anys. En eixe sentit, dins d'un clima generalitzat de crítica envers la gestió de la primera institució provincial, una sèrie de fets sobreeixiren per la seua gravetat i ressonància pública.

39 L'oposició del consistori vinarossenc a Heraldo de Castellón, 03 i 10/02/1921 i La Provincia Nueva, 10/02/1921. Les gestions dels parlamentaris castellonencs a El Clamor, 05/02/1921. L'aprovació del pressupost a Heraldo de Castellón, 17/03/1921 i Actes de la Comissió Provincial, 30/03/1921.

40 Vegeu per exemple Actes de la Diputació Provincial de Castelló, 22/01/1922 i 17/10/1922 , Heraldo de Castellón i La Provincia Nueva, 18/06/1923. 
Cronològicament, el primer episodi que mereix atenció és el referit a l'etapa de bloqueig que va viure la Diputació a partir de la primavera de 1918. Arran de la divisió del grup conservador, entre els ciervistes i els datistes -una altra facció conservadora d'abast estatal, encapçalada per Eduardo Dato- i l'abandonament d'aquestos darrers del pacte amb els liberals reverteristes $\mathrm{i}$ els carlins per passar a constituir una aliança amb els liberals cantistes, les dues noves coalicions resultants -ciervistes-reverteristes-carlistes per un costat i datistes-cantistes per l'altre- sumaven la mateixa quantitat de diputats, nou. Amb els dos diputats republicans instal.lats en la neutralitat, el resultat d'aquesta reestructuració de forces no va ser altre que la impossibilitat de constitució de cap majoria de govern.

L'obertura d'un nou període de sessions, en maig de 1918, va posar de manifest la situació de bloqueig per la qual la corporació provincial travessaria a partir d'aleshores i durant bastants mesos. A les successives convocatòries al ple acudien només els vuit diputats cantistes i el datista, nombre insuficient per poder celebrar sessió. ${ }^{41} \mathrm{~A}$ les darreries d'aquell mes la situació ja estava generant un malestar considerable, fins i tot en la premsa afí als partits que la estaven provocant. «Nos parece sencillamente abusivo, que a fecha que hemos llegado, próximo a finalizar el mes de Mayo, y en vísperas de las necesarias operaciones mensuales que impone la marcha y fines administrativos de la Diputación provincial, no se hayan reunido todavía los señores Diputados», assenyalava La Provincia Nueva, al temps que explicava que ni tan sols s'havia pogut escollir un president ni un vicepresident de la Comissió Provincial. ${ }^{42}$

Precisament, aquesta manca de vicepresident va fer que es generara una forta controvèrsia en torn a l'òrgan permanent de la Diputació, la Comissió Provincial, en el qual ara tenien majoria els datistes-cantistes. Els ciervistes-reverteristes-carlistes estimaven que no devia seguir funcionant amb un vicepresident accidental, el vocal de major edat, ja que aquest sols podia exercir com a tal en casos d'absència o de malaltia del titular. Així les coses, els dos diputats d'aquesta coalició -Goméz Cortés i Mingarro- decidiren no acudir més a les sessions de la Comissió Provincial mentre aquesta

41 Heraldo de Castellón, 03/05/1918.

42 La Provincia Nueva, 20/05/1918. Crítiques similars en Heraldo de Castellón, 15/06/1918. 
no passara a estar presidida per l'únic que, en aquelles circumstàncies, estimaven que estava legalment facultat per a fer-ho: el Governador Civil, en la seua condició de president nat d'aquell organisme. És més, interposaren recurs al Ministeri de Governació contra tots els acords presos per aquella Comissió Provincial constituïda, segons ells, il.legalment. ${ }^{43}$

Amb tot, a pesar del recurs i de l'absència de dos dels cinc diputats que integraven la Comissió Provincial, aquesta va continuar funcionant durant els mesos següents. No així el ple de la Diputació, que va romandre inactiv entre maig de 1918 i juliol de 1919. Fins a l'1 d'agost de 1919 no es va tornar a reunir. Molt abans, aquella situació d'inoperància administrativa de la corporació per motius polítics ja havia sigut qualificada de bochornosa. ${ }^{44}$ I és que ni tan sols s'havien pogut aprovar els pressupostos per a I'exercici 1919-20, durant el qual van seguir regint els de 1918.
Una segona fita en la marxa administrativa de la corporació provincial de ressonàncies especialment negatives va arribar a l'estiu de 1920. A principis d'agost les minories presentaren conjuntament una moció de censura contra el President i el Vicepresident de la Diputació -els liberals Manuel Giménez i Norberto Ferrer respectivament- per «[...] el abandono en que se ha tenido el ejercicio del cargo de ordenador de pagos, tanto por el señor presidente de la corporación como por el señor vicepresidente de la misma». Sembla ser que les perllongades absències d'ambdós havien provocat la paràlisi administrativa de la institució. Tanmateix, després d'una tempestuosa sessió plenària molt comentada a la premsa localambdues mocions foren retirades. ${ }^{45}$

En darrer terme, una tercera situació d'excepcional repercussió en la marxa administrativa de la Diputació $i$ en la seua imatge va ser la generada en torn a la gestió de la impremta, on es confeccionaven els

43 La Provincia Nueva, 17 i 19/06/1918. Vegeu també l'edició del dia 10/08/1918. Des de ben prompte -llei provincial de 16 de desembre de 1876, llei provincial de 2 d'octubre de 1877, llei provincial de 29 d'agosst de 1882- el règim de la Restauració havia retallat el grau d'autonomia assolit per les diputacions durant el Sexenni, en incrementar la seua dependència del Govern, a través de la figura del governador civil. A més de supervisar les seves actuacions, els governadors civils podien ajornar o suspendre les sessions de les corporacions provincials i els seus acords i presidien amb veu i vot les sessions del Ple i de la Comissió Provincial en aquelles ocasions en què decidien assistir-hi (SANTANA, M.: La diputación provincial en la España decimonónica. Instituto Nacional de Administración Pública, Madrid, p. 169; GonZÁlEZ, J. A.: Las diputaciones provinciales en España. Historia política de las Diputaciones desde 1812 hasta 1985. Mancomunidad General de Diputaciones de Régimen Común, Madrid, 1986, pp. 48-49). 
diversos impresos de la institució i sobretot el Boletín Oficial de la Provincia. Els problemes van emergir arran de la interposició d'una demanda $d^{\prime}$ 'augment salarial del $55 \%$ per part dels treballadors d'aquest establiment, per tal d'equiparar els seus emoluments a aquells que percebien els companys d'ofici que exercien en les impremtes privades de la ciutat. En la demanda s'incloïa també el termini de vuit dies per atendre-la, passat el qual s'aniria a la vaga.

La corporació, controlada en aquesta ocasió per una majoria conservadora ciervista, es va negar a acceptar la petició, en al.legar que fer-ho suposaria violar els pressupostos vigents així com determinades disposicions reglamentàries d'àmbit intern. Com a molt va oferir tenir en compte la demanda, al igual que les demés que en el mateix sentit havien sigut formulades per altres empleats provincials, a l'hora d'elaborar el nou pressupost. ${ }^{46}$

Expirat el termini fixat, el dia 13 d'octubre va començar la vaga i el dia següent el Boletín Oficial de la Provincia ja no eixia a la llum. La Diputació va comunicar als vaguistes que els considerava dimitits dels seus càrrecs i fins i tot, per majoria de vots -els del grup ciervista- va acordar que la impremta fora suprimida i el servei externalitzat, en esgrimir els diputats dretans que aquesta era econòmicament deficitària. Nogensmenys, sembla que aquest darrer acord no va arribar a complir-se, ja que fins a finals de març de 1922 no va tornar a ser publicat el butlletí, després que la Diputació cedira a les pretensions dels vaguistes i accedira a equiparar el seu sou al que percebien la resta de companys d'ofici. ${ }^{47}$

44 Vegeu l'article del corresponsal a Castelló del diari carlí valencià Diario de Valencia, reproduït a La Provincia Nueva, 27/07/1918.

45 Actes de la Diputació Provincial de Castelló, Heraldo de Castellón i La Provincia Nueva, 02 i 03/08/1920.

46 El plantejament i inici del conflicte a Actes de la Diputació Provincial de Castelló, La Provincia Nueva i Heraldo de Castellón, 10 i 11/10/1921.

47 L'inici de la vaga i la suspensió de la publicació del butlletí a Heraldo de Castellón, 13/10/1921 i Actes de la Comissió Provincial, 14/10/1921. Des del número corresponent al 9 d'octubre de 1921 fins a l'aparegut el 26 de març de 1922 només se'n van publicar dos, els dies 20 d'octubre i 5 de novembre. La resposta considerant els vaguistes dimitits a Actes de la Diputació Provincial de Castelló, 13/10/1921 i Heraldo de Castellón i La Provincia Nueva, 14/10/1921. La supressió de la impremta a Actes de la Diputació Provincial de Castelló, 05/12/1921 i Actes de la Comissió Provincial, 17/12/1921. El diputat ciervista Miguel Llansola va fixar el dèficit acumulat per la impremta entre 1912 i 1920 en 93.083 pessetes. Els diputats liberals Castelló i Tàrrega i Benjamín González, per contra, qüestionaren els comptes presentats per Llansola i la insolvència del citat establiment. La fi del conflicte i la reaparició del butlletí a Heraldo de Castellón, 25 i 27/03/1922. 
Es desconeixen els motius pels quals la Diputació va ser incapaç d'arribar abans a una solució perquè la confecció del butlletí fora represa. Però el cas és que durant més de cinc mesos aquesta publicació oficial va romandre suspesa, amb els consegüents trastorns dels diversos procediments administratius que s'havien d'anunciar, per imperatiu legal, en el Boletín Oficial. Així mateix, durant aquest prolongat període tampoc es pogueren publicar els avisos $\mathrm{i}$ informacions de molt diversa índole, que tant els diversos ministeris, com el Governador Civil, la Diputació, la Comissió Provincial, els ajuntaments i fins i tot entitats de caire particular donaven a conèixer a través del referit butlletí.

Pel que fa a la gestió de la funció bàsica que desenvolupava la Diputació, la benèfica, tampoc sembla que s'haguera avançat massa respecte al panorama dibuixat per Manuel Martí. Els establiments assistencials -Hospital, Casa de la Misericòrdia i Casa d'Expòsits- continuaven presentant un estat precari i una gestió deficient. Una bona prova la constitueix l'episodi del pressupost de l'arbitri de l'arròs recollit en pàgines anteriors. Una altra ens la proporciona el Governador Antonio Pineda de los Infantes, que al poc de prendre possessió del seu càrrec va voler conèixer a fons la situació d'aquestes institucions. Les conclusions del seu estudi les va fer públiques en sessió de la pròpia Diputació. De l'Hospital es va limitar a assenyalar que l'edifici era adequat però estava «a medio terminar», mentre que respecte a la Casa de la Misericòrdia va afirmar que «[...] me hice cargo de la necesidad de llevar a cabo muchas reformas para que no se tenga aquello como asilo de reclusión, sino como asilo de educación y de instrucción». ${ }^{48}$

En la mateixa línia, poc després, en el seu comentari a una memòria realitzada pel diputat liberal José Castelló Tárrega sobre l'estat d'ambdós establiments, La Provincia Nueva va assegurar que en ella quedava patent que l'Hospital requeria millores imprescindibles, mentre que a la Casa de la Misericòrdia regnava el desordre i l'anarquia. ${ }^{49} \mathrm{Amb}$ aquestes premisses no resulta sorprenent que els casos sòrdids i luctuosos - puntuals però de fort impacte públic- seguiren succeint-se de tant en tant en els establiments provincials. ${ }^{50}$ Aquest fosc panorama sembla

48 Actes de la Diputació Provincial de Castelló, 15/09/1919.

49 Les opinions de La Provincia Nueva a l'edició del dia 16/12/1919.

50 Es pot citar el cas de l'infant que va morir asfixiat dins d'una caixa en les dependències de l'Hospital, els leprosos que un dia deambularen lliurament pels carrers de la capital, la dement que es va suïcidar i de l'absència de la qual el personal de l'Hospital va tardar prou en adonar-se'n o la mort d'un altre dement també a l'hospital en circumstàncies confuses, suposadament a trets d'un policia. Un compendi d'aquestos fets a El Clamor, 12/07/1919. 
que era comú a bastants dels establiments benèfics mantinguts per les diputacions (Cayuela, Abad, 1999: 159-171; Martínez, Laguna, 1995: 259; Galván, 1994: 1201-1203).

\section{EMPLEATS, CONIRACTISTES I ASILATS: LA DipUTACIÓ COM A MAQUINÀRIA CLENTELAR}

Una de les raons principals de que controlar la Diputació, o almenys assolir una posició influent al seu si, esdevinguera objectiu primordial per a les forces polítiques, era les possibilitats que oferia aquesta institució com aparell clientelar. La nodrida nòmina d'empleats que tenia al seu servei -en torn al centenar- ${ }^{51}$ les seues variades funcions en l'esfera administrativa i la gestió d'establiments benèfics i assistencials de dimensions considerables -l'Hospital i la Beneficència principalment- proporcionaven múltiples oportunitats als polítics que regien els destins de la corporació provincial a l'hora d'alimentar les seves xarxes clientelars, mitjançat la manipulació discriminatòria de l'administració provincial en bene- fici dels seus afins, tal com altres autors també han posat de relleu (Esteban, 1991: 156).

Pel que fa a la col-locació de clients i amics polítics en la plantilla de la Diputació -tant en les pròpies dependències com en els establiments $\mathrm{i}$ organismes més o menys vinculats a la mateixa, com ara l'Hospital, la Beneficència, l'Institut, la Comissió Mixta de Reclutament...- resulta inviable obtenir xifres fiables sobre la proporció d'empleats provincials que devien el seu lloc de treball a aquesta pràctica. No obstant, les dades i testimonis que s'han pogut recopilar posen de manifest que l'empleomania va continuar estant plenament vigent en la corporació provincial durant aquells anys finals del període restauracionista, de manera similar a que d'altres estudis sobre la trajectòria $d$ 'aquestes institucions en la referida etapa han posat de relleu (Martínez, Laguna, 1995: 260; Pastrana, 1995: 60-61).

Es tracta d'informacions com ara el nomenament -per set vots a fa-

51 A la plantilla aprovada en sessió de la Diputació de 13 de març de 1920 figuraven un total de 118 treballadors. En aquesta xifra s'incloven, a banda del personal tècnic i administratiu d'oficina, les plantilles dels establiments provincials (Hospital, Beneficència, Impremta) i el personal subaltern (ordenances, vigilants, porters, personal de neteja, etc.). Per contra, segons les dades publicades a BeuLDo, M.: Anuario-guía de la provincia de Castellón. 1922. Editorial Diario de Valencia, València, 1922, pp. 77-81, el nombre d'empleats adscrits a la corporació provincial seria de 96. Cal tenir en compte, però, que en aquest recompte no es va computar el personal subaltern, que en la plantilla de març de 1917 ascendia a la xifra de 17 empleats. 
vor i sis en contra- de Rafael Ribés Gómez com a metge de guàrdia de l'Hospital, quasi al mateix temps que un parent seu, Arcadio Porcar Ribés, assolia la presidència de la Diputació. En 1922 Rafael Ribés continuava exercint com a metge d l'Hospital. Un altre cas similar es va donar quan, segons el setmanari republicà Rebeldía, el diputat conservador Ramón Salvador va voler imposar un metge recentment titulat i amb escassa experiència com a membre de la Comissió Mixta de Reclutament, per damunt d'un altre aspirant amb més mèrits acumulats. Temps després es va suscitar un enfrontament entre els grups liberal i ciervista de la corporació al voltant de quin era el metge que havia d'ocupar una plaça que havia quedat lliure a l'Hospital. Els dretans asseguraren que el candidat dels liberals -José Guallart Lluch-era parent del director del referit establiment provincial, el diputat conservador maurista Francisco Segarra. ${ }^{52}$

Però no sols a l'hora d'ocupar places de metges es poden detectar pràctiques de nepotisme. Així, en I'oficina de comptadoria figuraven dos germans de Norberto Ferrer Calduch, diputat provincial liberal durant el període estudiat. Es tracta de Ricardo -Cap de Negociat de Primera- i Luciano Ferrer Calduch, sobre la regularitat de la designació del qual com auxiliar en abril de 1921 es va estendre l'ombra del dubte. ${ }^{53}$ Altres dos casos en els quals tal volta els criteris clientelars jugaren un paper destacat foren els dels també liberals Alfonso Blanco Blasco i José Ortells Aparici. El primer va ocupar el càrrec de dipositari de la corporació almenys des de 1920, mentre que el segon eixe mateix any era cap de negociat de l'Hospital, on exercia com a secretari dos anys després. ${ }^{54}$

52 El nomenament de Rafael Ribés Gómez a Actes de la Diputació Provincial de Castelló, 08/05/1913. La seua presència en la plantilla de 1922 a BelliDO, M.: Anuario-guía de la provincia de Castellón. 1922, p. 79. (Rebeldía, 16/12/1917). El metge protegit per Ramón Salvador a Rebeldía, 16/12/1917. La disputa per l'ocupació d'una plaça de metge de l'Hospital a Actes de la Diputació Provincial de Castelló, 13/03/1920.

53 Actes de la Comissió Provincial, 09/04/1921 i Actes de la Diputació Provincial de Castelló, 15/04/1921.

54 La condició d'empleats de la Diputació de Blanco i Ortells a les plantilles accessibles en Actes de la Diputació Provincial de Castelló, 13/10/1920 i BeuIDO, M.: Anuario-guía de la provincia de Castellón. 1922, p. 79. La seua adscripció liberal es pot constatar ja a El Liberal, 02/01/1918 i 27/02/1918 respectivament. Es dóna la circumstància que José Ortells Aparici es va presentar a les eleccions provincials de 1923 en la candidatura liberal per Llucena-Viver i, en resultar escollit, va ocupar el càrrec de Director de l'Hospital Provincial (Vegeu Actes de la Diputació Provincial de Castelló, 03/08/1923). 
La rellevància d'aquesta funció clientelar de la Diputació dins l'entramat de la política caciquista es posa especialment de manifest a partir de determinats conflictes que suscitaren fortes tensions entre les diverses parts enfrontades. Així, en juliol de 1919 el Governador Víctor Ebro -representant de la coalició maurociervista que ocupava l'Executiu a la Cort- va arribar a suspendre un acord de la majoria de la Comissió Provincial -formada per datistes i liberals- en virtut del qual havien sigut nomenats tres nous empleats, en esgrimir que aquell organisme no estava facultat per dictaminar tals nomenaments. Manuel Mingarro, diputat carlista vocal de la Comissió Provincial, havia abandonat la polèmica sessió per mostrar-se disconforme amb els nomenaments acordats. Per la seua banda, La Provincia Nueva va assegurar que el grup majoritari a la Diputació s'havia repartit equitativament les tres designacions a efectuar, una per a Tiburcio Martín (conservador datista), l'altra per a Gómez Cortés (liberal reverterista) i l'altra per a José Tárrega Berenguer (liberal cantista). Heraldo de Castellón va anunciar que la Comissió Provincial anava a recórrer la providència d'anulació dictada per Ebro, va rebatre els arguments jurídics del Governador i va recordar un cas anterior similar en què les designacions havien sigut practicades pel bloc anticantista, format per conservadors i reverteristes. ${ }^{55}$

Cal fer notar també que es registra un flux de personal prou intens entre les redaccions dels diversos periòdics de la capital i les dependències de la Diputació. Així, Miguel Carlos Armengot Fernández, redactor $i$ en diverses etapes director de La Provincia i La Provincia Nueva-diari dels conservadors-almenys entre juliol de 1917 i octubre de 1921 va exercir el càrrec de secretari administrador de la Junta Provincial de Beneficència, remunerat amb 2.000 pessetes anuals. ${ }^{56}$

56 Actes de la Comissió Provincial, 19/04/1919 i Actes de la Diputació Provincial de Castelló, 13/10/1921. Probablement Heraldo de Castellón es referia a Armengot quan acusava a La Provincia de rebre una subvenció de la Diputació de 2.000 pessetes «[...] para no hacer nada» (Heraldo de Castellón, 18/11/1915). En el cas de Manuel Hernández Polo, les dades de què disposem situen la seua vinculació laboral amb la Diputació -ja constatada en gener de 1918-abans que la seua ocupació com a redactor en cap de La Provincia Nueva, en 1921. Amb tot és cert que va compatibilitzar ambdós treballs. Vegeu respectivament Actes de la Comissió Provincial, 04/01/1918 i La Provincia Nueva, 26/08/1921. Tampoc sabem si el càrrec de mecanògraf que ocupava Francisco Vilarroig Asensi a la secretaria de la Diputació tenia alguna relació amb el fet que era, des de feia anys, membre de la redacció d'Heraldo de Castellón (Heraldo de Castellón, 12/12/1922 i 12/05/1923). 
Un cas controvertit fou el de Manuel Gaya, redactor d'Heraldo de Castellón. La polèmica va saltar quan, a pesar d'ocupar un lloc de treball situat a la part baixa de l'escalafó de la Diputació -escrivent temporal- Gaya va ser designat inspector de l'Hospital i dels serveis de beneficència, càrrec que fins aleshores no figurava en la plantilla. Després de remarcar la paradoxa que un empleat temporal anara a fiscalitzar la gestió dels directors de l'Hospital i de la Beneficència -que eren diputats provincials- La Provincia Nueva va assenyalar com a veritable motiu d'aquella maniobra el desig d'assignar a Gaya una tasca -la d'inspecció- que no requeria una dedicació contínua ni sotmetre's a un horari de treball fix, circumstàncies que facilitarien la seva compatibilització amb la labor que desenvolupava al periòdic liberal, «[...] que tendrá un redactor bien pagado... con el dinero de la Diputación». ${ }^{57}$

Quant a l'acomiadament de treballadors per motivacions d'origen clientelar, durant el període estudiat certament no es registraren episodis tan espectaculars com aquell que es va donar a principis de 1910, quan en una cèlebre sessió de la Diputació es van acordar cessar a trenta-nou empleats. Tanmateix, el ball d'empleats al compàs dels canvis d'hegemonies polítiques que periòdicament es produïen al si de la corporació no s'havia detingut. Així, des de la seua posició neutral, en novembre de 1915 la premsa republicana assenyalava que en una sessió recent de la Diputació s'havia procedit al «[...] descuaje de aquellos empleos que, además de creerlos innecesarios la minoría liberal, están regidos por significados cosieros», entre ells el de director de camins provincials i el d'ajudant de l'arquitecte provincial, a més de suprimir el sou del secretari de la Junta Provincial de Beneficència i rebaixar el del propi arquitecte. ${ }^{58}$

Per la seua banda, anys després els liberals cantistes es queixaren del cessament, segons la seva versió per motius també estrictament polítics, de Manuel Adell Gutiérrez -Oficial Major de Secretaria- i Luciano Ferrer Calduch -que con s'ha comprovat anteriorment tornaria a ser reintegrat a la plantilla en 1921-. Aquells acomiadaments havien sigut aprovats per una Comissió Provincial dominada pel bloc anticantista (liberals reverteristes, conservadors i carlins). ${ }^{59}$

En qualsevol cas, els diversos episodis exposats al llarg dels pa-

57 La Provincia Nueva, 18 i $21 / 10 / 1919$.

58 El Clamor, 23/11/1915.

59 Heraldo de Castellón, 22/07/1919. 
ràgrafs precedents posen de relleu que en la configuració de la plantilla d'empleats de la Diputació no intervenien únicament criteris organitzatius i funcionals sinó també d'altres de naturalesa clientelar. És així com, tal com es venia donant des de les primeres dècades de la Restauració, la nòmina de treballadors de la corporació provincial es trobava sobredimensionada. D'eixa manera, per exemple, a finals de 1916 El Clamor es queixava de l'elevat cost que suposava la Diputació per als municipis, que l'havien de mantenir a través del contingent, degut a l'excés d'empleats que tenia, provocat perquè cada grup polític tractava d'acomodar a la seua clientela. ${ }^{60}$

En eixe sentit, i al igual que ja es posa de manifest a l'estudi de Martí, els intents per retallar la plantilla amb l'objectiu d'adequar-la a la càrrega de treball existent acabaven en fracàs. Durant el període que ací ens ocupa es registra una d'aquestes temptatives, la protagonitzada pel diputat ciervista Miguel Llansola a principis de 1920. Davant la proposta de plantilla dissenyada per la Comissió de Governació, amb un total que superava àmpliament els 110 empleats, Llansola va presentar una proposició alternativa, que no superava els 95 treballadors.
Respecte a la presentada per la referida comissió va assenyalar que «[...] las plantillas de empleados no deben formarse con miras a las personas ni para solventar compromisos antiguos por medio de jubilaciones y creación de destinos».

Només dos dels correligionaris de Llansola, Luis Fabra i Manuel Mingarro, li donaren suport. Fins i tot un altre membre del grup ciervista, Manuel Breva, es va encarregar de rebatre els càrrecs formulats per aquell contra la proposta de la Comissió de Governació - de la qual Breva formava part- i va assenyalar que «[...] lo propuesto por el Sr. Llansola equivale a la guillotina de la cabeza de la mayor parte de empleados provinciales, no estando dispuesto a actuar de verdugo de los mismos». De res li va valdre a Llansola acceptar que les amortitzacions de places que implicava la seua proposta es realitzaren progressivament. Aquesta va ser desestimada. ${ }^{61}$

Poc abans de l'arribada de la dictadura primorriverista encara va haver, no un intent, però sí un suggeriment d'adequació de la plantilla de la Diputació. En aquest cas va venir del Governador Civil, el liberal Gómez Valdivia, que en el seu discurs inaugural de la nova corporació constituïda arran de les

60 El Clamor, 06/12/1916.

61 Actes de la Diputació Provincial de Castelló, 20 i 21/02/1920. 
eleccions provincials celebrades en juny de 1923, va evocar l'anomenat Reial Decret Elduayen de 1892, que havia fixat les plantilles que corresponien a cada província segons la seua categoria. El President, el també liberal Gómez Aparici, li va respondre que «[...] como hay una plantilla aprobada [l'acordada en febrer de 1920] es ello un obstáculo para acometer ciertas reformas». Per la seua banda, des de I'oposició ciervista Manuel Breva li va recordar que «[...] respecto a los asuntos de personal intervienen siempre intereses políticos que dificultan las reformas y más aún porque existe una plantilla formada por el Partido Liberal que será el llamado a realizarlas». .2

No obstant, sí que cal prendre en consideració cert avanç que la Diputació va realitzar en la línia de promoure una major regulació de les condicions laborals dels seus empleats, orientada a desterrar de la gestió del personal els criteris clientelars i les arbitrarietats. Un primer pas es va donar també en març de 1920, quan al temps que s'aprovava la distribució dels empleats en els llocs definits en la plantilla que s'havia aprovat en febrer, es va declarar la inamobilitat $d^{\prime}$ 'aquells que ocupaven els càrrecs d'oficial major de secretaria, caps de negociat de primera i de segona, aspirants de primera i de segona i mecanògrafs.

Si atenem a les dades exposades pel diputat Norberto Ferrer durant el debat sobre la qüestió de la inamobilitat -va assegurar que només Castelló i una altra diputació encara no havien atorgat aquesta condició als seus empleats- no es pot afirmar que fóra una mesura precisament pionera. A més, només va afectar als treballadors que ocupaven els càrrecs abans assenyalats, un total de 30 dels 118 empleats que composaven la plantilla. ${ }^{63}$ No van ser declarats inamovibles els auxiliars i subalterns, la major part dels empleats de l'Hospital i de la Beneficència, els de la Impremta, etc. Tanmateix, no es pot negar que anava orientada a dificultar el ball d'empleats impulsat per les trames clientelars. A més, posteriorment, en febrer de 1921, es va acordar ampliar la inamobilitat al personal subaltern, als auxiliars, al tenedor de llibres i al delineant. ${ }^{64}$

Aquesta línea d'actuació encetada amb la instauració de la inamobilitat per a determinats empleats es va culminar uns mesos després amb l'aprovació del Reglamento del Cuerpo de Funcionarios de la Excma. Diputación Provincial. En

62 Actes de la Diputació Provincial de Castelló, 03/08/1923.

63 Ibidem, 13/03/1920.

64 Ibidem, 26/02/1921. 
octubre de 1920 es va aprovar el títol I, Disposiciones generales, en el qual quedaven regulats aspectes com l'amortització de vacants, el procediment de provisió de places -tant per promoció interna com per provisió externa- jubilacions, quinquennis, horaris de les oficines, sancions als empleats, estructura orgànica de les oficines, llicències, baixes per malaltia o accident, pensions de viduïtat, etc. Per exemple, es disposava que les vacants s'haurien de cobrir mitjançant concurs de mèrits o concurs-oposició, excepte les del personal subaltern -porters, ordenances i vigilants- que podrien ser designats per la Diputació sense necessitat de concurs. ${ }^{65}$ La tasca es va culminar en abril de 1921, amb l'aprovació dels títols II a V del referit reglament, dedicats cadascun d'ells a definir les funcions i competències de cada departament $i$ de cada negociat en què s'articulava l'administració provincial, així com de cadascuna de les ocupacions que integraven els diversos negociats. 66

La rellevància atorgada pels propis protagonistes a aquest reglament va ser patent. Una vegada sancionat el títol I, el diputat Nor- berto Ferrer va prendre la paraula per felicitar a tots els diputats que havien participat en la sessió,

[...] que será memorable en la historia de la corporación provincial, por primera vez se han despojado todos los señores diputados del interés personal para corroborar [sic] en una obra de interés para la corporación y de auxilio para los funcionarios que la sirven, obra que por su perfección estimó merecía ser copiada por otras corporaciones.

Amb tot, és cert que no sembla que l'aplicació del referit reglament, en els seus primers mesos de vigència, fóra precisament modèlica, si fem cas de les declaracions de qui havia sigut el seu principal impulsor, José Castelló Tárrega, diputat liberal i director d'Heraldo de Castellón, en sessió celebrada menys d'un any després de l'aprovació del títol I: «La única cosa buena que hizo la última Diputación, me refiero al reglamento y plantillaje de los funcionarios de la corporación, está ya prostituido». ${ }^{67}$ Així mateix, també és cert que el reglament sols afectava als llocs de treball burocràtics, no al personal tècnic dels establiments provincials, com ara els metges, els

65 Actes Diputació Provincial de Castelló, 26/10/1920.

66 Ibidem, 15/04/1921.

67 Les declaracions de Norberto Ferrer a Actes de la Diputació Provincial de Castelló, 26/10/1920. Les de Castelló Tàrrega a Actes de la Diputació Provincial de Castelló, 03/08/1921 i Heraldo de Castellón, 04/08/1921. 
practicants, els professors de la Beneficència, etc. ${ }^{68}$

No obstant, no es pot negar que l'elaboració i aprovació del reglament va suposar un impuls considerable cap al reforçament de criteris tals com l'eficiència, l'equilibri entre recursos disponibles $i$ càrregues de treball, el mèrit o l'antiguitat a l'hora de gestionar el personal de la Diputació, en detriment del clientelisme i l'arbitrarietat. Iniciatives anteriors, recollides a l'estudi de Martí, havien sigut promulgades per grups que ocupaven posicions minoritàries al si de la Diputació i no havien passat del grau de temptativa. Per contra, en aquesta ocasió el reglament, nascut com una aspiració personal de Castelló Tárrega, havia sigut consensuat pels grups polítics principals -el liberal-datista i el conservador ciervista, que integraven la Comissió de Governació autora de la proposta definitiva- i aprovat per unanimitat.

Per altra part, a banda de la nòmina d'empleats, la Diputació oferia altres possibilitats d'afavorir als amics i clients polítics. Una d'elles venia donada pels contractes dels subministraments i serveis necessaris per al desenvolupament d'algunes de les seues funcions. Nogensmenys, les dificultats dels contractistes de la Diputació en cobrar els seus emoluments i el fet que l'activitat de la mateixa en matèria de construcció i conservació d'obres públiques fóra molt limitada, va fer que els casos i sospites de manipulació clientelar dels processos de contractació foren escassos.

L'únic episodi al voltant del qual s'ha pogut constatar que es va generar certa polèmica es va originar arran de l'acord de la Diputació, pres el 12 de maig de 1915, de rescindir el contracte de l'arrendatari del cobrament del contingent, el liberal Juan Rambla Viñes. La Provincia va orquestrar una campanya contra el referit acord, aprovat amb els vots de la majoria liberal i també dels republicans. Segons el diari conservador l'arrendatari, alarmat per l'escassa recaptació de contingent que estava aconseguint, havia sol.licitat la rescissió del contracte, que havia sigut concedida per la Diputació no per raons de justícia sinó per un acte de nepotisme i favoritisme $\mathrm{i}$ en perjudici dels interessos econòmics de la corporació. ${ }^{69}$

La reacció dels liberals va ser contundent. En una carta dirigida al Governador Civil -i publicada a Heraldo de Castellón- sense respondre en cap moment a les acusacions vessades per La Provincia, demanaren a la referida autoritat que denunciara al jutjat els números del 
referit diari -i dels periòdics carlins El Maestrazgo i Diario de Valencia, que s'hi havien sumat a la campanya- a qui acusaven de calúmnies $\mathrm{i}$ difamacions. ${ }^{70}$

En darrer terme, una altra esfera d'activitat de la Diputació que havia donat peu a maquinacions clientelars havia sigut la dels establiments benèfics, en concret la pràctica de manipulacions per afavorir l'ingrés com asilats $d^{\prime}$ individus que no complien els requisits per tenir tal condició o que foren afavorits per davant d'altres que presentaven nivells de pobresa superiors. Tanmateix, el ben cert és que al llarg del període que comprén el present estudi només s'ha trobat una breu referència a l'ús clientelar relacionat amb aquesta qüestió. A l'estiu de 1919, en plena sessió de la Diputació, el liberal José Tárrega afirmava que hi havia gran quantitat de malalts que ingressaven a l'Hospital però que en realitat no eren pobres, «[...] y sobre todo de Castellón que presentaban certificados de pobreza defectuosos o expedidos indebidamente por los alcaldes de barrio». L'afer no va tenir més recorregut que la protesta de rigor contra les paraules de Tárrega d'un dels diputats republicans, Joaquín Vicent, que no podia deixar passar que s'atacara el bon nom de l'Ajuntament, dominat pels seus correligionaris des de feia anys. ${ }^{71}$

En qualsevol cas, no resulta possible discernir si l'absència d'informacions i testimonis sobre aquest tipus de manipulacions clientelars relacionades amb els establiments provincials es devia a una manca real de casos o més aviat a que es tractava de situacions que a aquelles alçades es trobaven assumides per totes les instàncies $i$ ja no suscitaven quasi mai cap tipus de polèmica.

\section{La Diputació, la Comissió Provin- CIAL I EL CONTROL DELS PODERS LOCALS}

A banda de les diverses competències $i$ funcions que, tal com s'ha fet patent al llarg dels punts anteriors, desenvolupaven les diputacions, i de l'ús clientelar que els diputats provincials feren de les seves atribucions, s'ha de fer referència també al paper d'aquestes institucions com a instàncies de control dels poder locals. Les corporacions provincials tenien àmplies facultats en aquesta matèria, sobretot el seu òrgan permanent, la Comissió Provincial, que aprovava i reformava les ordenances municipals; quan la Diputació no es trobava reunida, podia revisar els acords presos pels ajuntaments i girar visites $d^{\prime}$ inspecció als mateixos per examinar l'estat dels seus serveis, dels comptes mu-

70 Heraldo de Castellón, 09/06/1915.

71 Actes de la Diputació Provincial de Castelló, 06/08/1919. 
nicipals i de l'arxiu i, una vegada valorats els resultats de les referides visites, adoptar les mesures que estimara adequades per millorar l'administració municipal; resolia els recursos d'alçada interposats contra acords presos pels consistoris; aprovava els comptes dels ajuntaments; gestionava l'aplicació de les contribucions estatals; entenia sobre la unificació o segregació de termes municipals; podia intercedir en disputes entaulades entre pobles veïns; i disposava d'àmplies competències respecte als comicis municipals, ja que decidia en sobre la validesa dels censos i del desenvolupament i resultat final dels processos electorals (Tusell, 1973: 31; Santana, 1989: 169-170)..$^{72}$

No és d'estranyar, doncs, que el control de la Diputació, i més encara el de la Comissió Provincial constituïda per cinc diputats, un per cada districte electoral, normalment escollits entre els cacics comarcals més influents en cada moment- fóra objectiu principal de totes les forces polítiques (Pastrana, 1995: 61-65). De l'afinitat amb la majoria que governava aquest organisme depenia en bona mesura que un cacic local donat mantinguera el domini en el seu municipi o comarca. I és que, tal com el setmanari vinarossenc Patria va expressar literàriament en un dels seus números, la corporació provincial «[...] no es otra cosa que el castillo feudal de los profesionales de la política, de donde parten las raíces que alimentan y sostienen a los caciques rurales». ${ }^{73}$

D'altra banda, és cert que els casos que transcendiren a l'esfera pública d'utilització espúria de les àmplies facultats de la Comissió Provincial, amb mires a beneficiar determinats interessos polítics, es centren en l'àmbit electoral. Tal volta aquesta circumstància es deu a que precisament aquesta matèria, l'electoral, suscitava major expectació mediàtica que la resta d'àrees d'actuació de l'administració local.

En l'esfera electoral la Comissió Provincial tenia la facultat de resoldre, en segona instància -després de la Junta Municipal del Cens Electoral- les reclamacions interposades en els comicis municipals. Com ha sigut posat de relleu en un altre lloc, en cadascuna de les cinc convocatòries municipals del període estudiat foren nombroses les reclamacions elevades a aquest òrgan provincial permanent, reclamacions que en un percentatge considerable -que va oscil.lar entre el $28 \mathrm{i}$ el $50 \%$-eren estimades. Però allò que en aquest punt cal remarcar són els baixos percentatges que assoliren les resolucions preses per unanimitat en aquesta matèria. Els valors no superen en cap convocatòria el $30 \%$

72 Vegeu també la Llei Provincial de 29 d'agost de 1882, capítols VII i VIII.

73 Patria, 15/05/1921. 
i en la majoria d'elles no passen del $20 \%$. Es posa de manifest doncs la incapacitat de la Comissió Provincial per fixar criteris sòlids a l'hora de valorar les reclamacions electorals. Per contra, aquestes xifres apunten a que foren les motivacions partidistes les que decantaren els vots dels membres de la Comissió en un sentit o en l'altre (Llansola, 2016).

La revisió de les resolucions de les reclamacions electorals ve a confirmar els extrems apuntats en el paràgraf anterior. La major part de les reclamacions eren resoltes mitjançant votació, en la qual els diputats del partit o coalició que disposava de la majoria es decantaven per estimar o desestimar la reclamació, mentre que els de la formació o aliança minoritària optaven per I'alternativa contrària. Només els diputats republicans que en alguna etapa van ser membres de la Comissió Provincial es mantingueren, en termes generals, apartats d'aquesta tònica, alineant-se en ocasions amb la postura dels diputats que representaven a la força hegemònica $i$ en altres amb el posicionament del grup minoritari (Llansola, 2016).

\section{Conclusions}

Arribats a aquest punt, un balanç de l'anàlisi realitzada sobre la labor desenvolupada per la Diputació en les diverses facetes, porta a concloure que les seues premisses i línies d'actuació, limitacions, problemàtiques $\mathrm{i}$ carències a penes havien variat respecte a les posades de manifest per Manuel Martí en el seu estudi de l'evolució de la corporació provincial castellonenca durant els primers decennis de la Restauració.

En el plànol econòmic, l'erari de la Diputació va seguir acusant les mateixes debilitats de sempre, agreujades per la configuració d'una conjuntura econòmica negativa que va afectar a bona part del territori castellonenc i per la perpètua utilització de la hisenda provincial amb fins clientelars. Mentre en I'articulació d'iniciatives i campanyes per fer front als múltiples i greus problemes econòmics i socials del període ocupava una posició secundària, la seua gestió de les infraestructures i serveis sobre els quals tenia responsabilitats, en termes generals va continuar estant presidida per la precarietat, la ineficiència $i$ la subordinació de les iniciatives desenvolupistes i assistencials als interessos partidistes i caciquistes. I pel que fa al paper de la Diputació i de la Comissió Provincial com a agents de dominació política dels municipis, a través de les àmplies facultats que tenien legalment assignades en el terreny de la supervisió i control dels ajuntaments, res fa pensar que s'haguera vist difuminat en alguna mesura.

És cert, però, que en una altra esfera d'acció, la de la gestió del personal adscrit a les seves dependències i establiments, sí que es donaren certs avanços contra l'ús de 
l'administració provincial amb mires clientelars i nepotistes. Així cal entendre la concessió de la inamobilitat en març de 1920 a determinats empleats -ampliada uns mesos després- i, sobre tot, l'aprovació, per unanimitat, del Reglamento del Cuerpo de Funcionarios de la Excma. Diputación Provincial, entre octubre de 1920 i abril de 1921. No obstant, les tardanes dates en què aquestes disposicions foren acordades impedeixen avaluar la seua repercussió i ben prompte es denunciaren violacions de les mateixes. Així mateix, cal recordar també que el referit reglament no afectava a tots els llocs de treball adscrits a la Diputació. En tot cas, es pot afirmar que durant el període 1913-1923 la configuració i gestió de la plantilla d'empleats de la corporació va seguir fortament mediatitzada per la intervenció de criteris de naturalesa clientelar.

Pel demés, en relació a d'altres tipus de manipulacions caciquistes, com ara les comeses a l'hora d'adjudicar i gestionar contractes de subministraments, serveis o obres o en els tràmits d'ingrés en els establiments benèfics, del fet que els testimonis i les informacions recollides siguen escassos, no es pot deduir una evolució cap a un major pes de valors com l'honestedat i la rectitud administrativa en l'administració provincial.

Així les coses, no és d'estranyar que el darrer President de la Diputació en l'època de la Restauració, el liberal Joaquín Gómez Aparici, en el seu discurs de presa de possessió, continuara remarcant la forta dependència de l'erari provincial envers el contingent provincial, per fer front a unes despeses cada vegada més elevades a causa de l'augment de les subsistències i dels sous dels empleats; fixara l'Hospital i la Beneficència com «[...] las dos únicas funciones importantes que le quedan a la Diputación», a banda de la recaptatòria; i, en assenyalar que la seua intenció era remeiar en la mesura que fóra possible els mals de la corporació, afirmara que «[...] aquí se suele tropezar con los intereses creados». ${ }^{74}$ La imatge $d^{\prime}$ ineficiència, de precarietat i de ser el centre neuràlgic de les trames caciquistes que la Diputació s'havia forjat des dels inicis del període restauracionista, no va variar durant aquella darrera dècada de vida del règim. D'eixa manera, no sols en la premsa contrària a aquest sinó també en medis periodístics apolítics es podien llegir propostes relatives a la desaparició de les diputacions, qualificades d'organismes inútils i antiquats. $^{75}$ 


\section{Bibliografia}

ABAD, V. (1988): La Taronja (17811939). Alfons El Magnànim, València.

AlCÁZAR, J. del (1989): Temps d'avalots al País Valencià (1914-1923). Diputació de València, València, AlíA, F. i SÁnchez, I. (1999): "La hacienda provincial", en I. Sánchez (coord.), Historia de la Diputación Provincial de Ciudad Real (18351999). Diputación Provincial de Ciudad Real, Ciudad Real, pp. 33-96.

Alós, V. R. i Castellet, C. (1998): El ocaso del sistema canovista. Elecciones generales en Castellón 19031923. Diputació de Castelló, Castelló de la Plana.

BeLIDO, M. (1922): Anuario-guía de la provincia de Castellón. 1922. Editorial Diario de Valencia, València.

Cayuela, J. G.. i Abad, P. (1999): "Poder provincial y sociedad", en I. Sánchez (coord.), Historia de la Diputación Provincial de Ciudad Real (1835-1999). Diputación Provincial de Ciudad Real, Ciudad Real, pp. 147-185.

EsteBAN, M. (1991): De la beneficencia a la previsión. La acción social en Salamanca (1875-1898). Diputación de Salamanca, Salamanca.

FusI, J. P. (1997): “Dictadura y democracia en el siglo XX", en T. Carnero (ed.), El reinado de Alfonso XIII. Ayer, n 28, pp. 15-28.

Galván, E. (1994): Historia de la Diputación Provincial de Canarias. Tesi doctoral, Universidad de Las Palmas de Gran Canaria.
Garrido, S. (1987): "Els efectes de la Primera Guerra Mundial a la Plana: la crisi municipal de Vila-real de 1917". I Congrés d'Estudis d'Història de la Plana, pp. 123-133.

González, J. A. (1986): Las diputaciones provinciales en España. Historia política de las Diputaciones desde 1812 hasta 1985. Mancomunidad General de Diputaciones de Régimen Común, Madrid.

Llansola, G. (2006): Republicanisme, identitat popular i hegemonia municipal. Castelló de la Plana, 1913-1917. Universitat Jaume I, Castelló de la Plana.

(2016): "Anatomia de la manipulació electoral: l'exercici del sufragi a Castelló en l'ocàs del sistema restauracionista (1913-1923)". Estudis Castellonencs, núm. 1 (2na època), pp. 261-301.

Martí, M. (1991): "Las diputaciones provinciales en la trama caciquil: un ejemplo castellonense durante los primeros años de la Restauración". Hispania, 179, Madrid, pp. 993 1041.

Martínez, F. A. i laguna, A. (1995): "La gestión menguante: entre la estabilidad administrativa y el fracaso autonomista (1902-1923)", en M. Chust (dir.), Historia de la Diputación de Valencia. Diputació de València, València, pp. 241-302.

Martorell, M. i Rey, F. del (2006): "El parlamentarismo liberal y sus impugnadores", Ayer, n ${ }^{\circ}$ 63, pp. 23-52.

Moreno, J. (2014): "Los partidos 
gubernamentales y el Rey, 19131923", en F. J. Romero i A. Smith (eds.), La agonía del liberalismo español. De la revoliución a la dictadura (1913-1923). Comares, Granada, pp. 31-56.

Pastrana, H. (1995): "El control de las diputaciones por los caciques regionales. La Diputación vallisoletana de la Restauración". Investigaciones históricas: Época moderna y contemporánea, $\mathrm{n}^{\circ} 15, \mathrm{pp}$. 55-66.

Piqueras, J. A. i Sanz, V. (1995): "La diputación en la Restauración (1875-1902", en M. Chust (dir.), Historia de la Diputación de Valencia. Diputació de València, València, pp. 209-239.

Rey, F. DEL (1998): "Las voces del antiparlamentarismo conservador», en M. Cabrera (coord.): Con luz y taquígrafos. El Parlamento en la Restauración (1913-1923). Taurus, Madrid, pp. 273-328.

Roldán, S. i García Delgado, J. L. (1973): La formación de la sociedad capitalista en España. 19141920. Confederación Española de Cajas de Ahorro, Madrid.

ROMEU, F. (1964): "La crisis de 1917 y sus consecuencias económicas y sociales en la región valenciana". Saitabi, n 14, pp. 111-132.
SANTANA, M. (1989): La diputación provincial en la España decimonónica. Instituto Nacional de Administración Pública, Madrid,

Santos, A. (2013): La Diputación Provincial de Albacete. La relación de la Diputación con la provincia. Evolución de las competencias de la institución provincial entre 1876 1999. Tesi doctoral, Universidad Nacional de Educación a Distancia. SOler, V. (1984): Guerra i expansió industrial: País Valencià (19141923). Alfons el Magnànim, València.

Tusell, J. (1973): La reforma de la administración local en España (1900-1936). Instituto de Estudios Administrativos, Madrid.

Vallejo, R. (2007): "La ciudadanía social", en M. Pérez Ledesma (dir.), De súbditos a ciudadanos. Una historia de la ciudadanía en España. Centro de Estudios Políticos y Constitucionales, Madrid, pp. 545-591.

ZURITA, R. (1996): Notables, políticos y clientes. La política conservadora en Alicante. 1875-1898. Conselleria de Cultura, Educació i Ciencia / Institut de Cultura Juan Gil-Albert, Alacant. 